\title{
Low Oxidative Stress-Mediated Proliferation Via JNK-FOXO3a-Catalase Signaling in Transplanted Adult Stem Cells Promotes Wound Tissue Regeneration
}

\author{
Neha R. Dhoke,, Ramasatyaveni Geesala, ${ }^{1,2}$ and Amitava Das ${ }^{1,2}$
}

\begin{abstract}
Aims: Stem cells exposed to pathological levels of reactive oxygen species (ROS) at wound sites fail to regenerate tissue. The molecular mechanism underlying differential levels of ROS-mediated regulation of stem cells remains elusive. This study elucidates the mechanistic role of catalase at $10 \mu M \mathrm{H}_{2} \mathrm{O}_{2}$-induced proliferation of mouse bone marrow stromal (BMSC) and hematopoietic (HSPC) stem/progenitor cells.

Results: BMSCs and HSPCs depicted an increased growth rate and colony formation, in the presence of $10 \mu M$ but not $100 \mu M$ concentration of $\mathrm{H}_{2} \mathrm{O}_{2}$, an effect that was perturbed by Vit. C. Mechanistically, JNK activationFOXO3a nuclear translocation and binding of FOXO3a to catalase promoter at $10 \mu M \mathrm{H}_{2} \mathrm{O}_{2}$ led to an increased expression and activity of anti-oxidant gene, catalase. This was followed by an increased proliferative phenotype via the AKT-dependent pathway that was perturbed in the presence of catalase-inhibitor, 3aminotriazole due to an increased ROS-mediated inactivation of AKT. Preclinically, $10 \mu M \mathrm{H}_{2} \mathrm{O}_{2}$-mediated preconditioning of BMSCs/HSPCs transplantation accelerated wound closure, enhanced catalase expression, and decreased ROS levels at the wound site. Transplantation of male donor cells into female recipient mice or GFP-labeled BMSCs or HSPCs depicted an increased engraftment and proliferation in preconditioned cell transplanted groups as compared with the wound control. Wound healing occurred via keratinocyte generation and vascularization in preconditioned BMSCs, whereas only neo-vascularization occurred in the preconditioned HSPCs transplanted groups.

Innovation and Conclusion: Our study suggests a distinct role of catalase that protects BMSCs and HSPCs from low ROS and promotes proliferation. Transplantation of preconditioned stem cells enhanced wound tissue regeneration with a better antioxidant defense mechanism-as a therapeutic approach in stem cell transplantation-mediated tissue regeneration. Antioxid. Redox Signal. 28, 1047-1065.
\end{abstract}

Keywords: ROS, JNK-FOXO3a, catalase, BMSC/HSPC engraftment, keratinocyte generation \& neovascularization, wound tissue regeneration

\section{Introduction}

$\mathbf{O}$ XIDATIVE STRESS IN CELLS results from the imbalance between the generation and clearance of oxidants. Accumulation of intracellular reactive oxygen species (ROS) often leads to disease and cell apoptosis. Harmful effects caused by ROS on the cells result in DNA damage, lipid peroxidation, protein oxidation, and oxidation of co-factors, thereby inactivating specific enzymes and leading to patho- logical consequences (42). Several disease conditions such as atherosclerosis, diabetes, neurodegenerative diseases, cancer, and chronic wounds are associated with increased ROS. In contrast to the damaging effects of ROS, recent studies also implicate a beneficial role of ROS at a lower concentration to the cellular physiology (42). Also, the source and type of ROS as well as their amount and duration of exposure in various sub-cellular localizations state their biological effect. Emerging evidence suggests that ROS act as an

\footnotetext{
${ }^{1}$ Centre for Chemical Biology, CSIR-Indian Institute of Chemical Technology, Hyderabad, India.

${ }^{2}$ Academy of Scientific and Innovative Research (AcSIR), New Delhi, India.
} 


\section{Innovation}

Bone marrow-derived bone marrow stromal stem/ progenitor cells (BMSCs) and hematopoietic stem and progenitor cells (HSPCs), when exposed to $10 \mu M$ concentration of $\mathrm{H}_{2} \mathrm{O}_{2}$, regulate the survival signaling mechanisms, thereby increasing proliferation, an effect that was perturbed by exogenous antioxidants. Mechanistically, an activation of JNK-FOXO3a signaling led to an increased expression and activity of catalase that, in turn, regulated the AKT activation-mediated proliferative phenotype of these cells. Transplantation of preconditioned BMSCs/ HSPCs with $10 \mu M$ concentration of $\mathrm{H}_{2} \mathrm{O}_{2}$ efficiently regenerated wound tissue via enhanced engraftment, proliferation, re-epithelization, and angiogenesis. This study offers a therapeutic approach for improved wound healing by preconditioning the stem cells, which equips them with a better antioxidant defense system.

important second messenger in tightly controlled signal transduction networks (38). ROS activate various physiological processes, including growth factor-mediated proliferation, angiogenesis, which involves activation of PI3K/ AKT, MAPK/ERK, and JNK pathways (40). A complex equilibrium of ROS production exists that is temporally and spatially regulated by a fine-tuned balance between ROS generation systems and antioxidant enzymes (29). Redox regulations in cells are maintained by antioxidant enzymes that are located at different cellular compartments that convert superoxide into hydrogen peroxide $\left(\mathrm{H}_{2} \mathrm{O}_{2}\right)$ and finally into water and molecular oxygen (27). The function of these antioxidant enzymes is dependent on the reaction kinetics, which, in turn, depends on the rate of reaction with $\mathrm{H}_{2} \mathrm{O}_{2}$, the concentration of $\mathrm{H}_{2} \mathrm{O}_{2}$, and enzymes in vivo. In addition, intracellular low-molecular-weight antioxidant, Vit. C is also known to protect the cells by quenching the free radicals (28).

Usually, cells generate $\mathrm{H}_{2} \mathrm{O}_{2}$ by the mitochondrial respiratory chain and NADPH oxidase, which is regulated by the glutathione system. Adult stem cells of bone marrow such as bone marrow stromal stem/progenitor cells (BMSCs) and hematopoietic stem/progenitor cells (HSPCs) are often exposed to different physiological levels of ROS such as $\mathrm{H}_{2} \mathrm{O}_{2}$. The low concentration of $\mathrm{H}_{2} \mathrm{O}_{2}$ in adult stem cells promotes their stemness and self-renewal capability (31). In contrast to HSPCs, myeloid committed progenitor cells are known to have a higher level of $\mathrm{H}_{2} \mathrm{O}_{2}$ (31). Thus, cellular response to $\mathrm{H}_{2} \mathrm{O}_{2}$ differs from cell to cell. However, the molecular mechanisms of cellular defense system against $\mathrm{H}_{2} \mathrm{O}_{2}$ in these adult stem cells are not yet clearly defined.

In our recent study, we extensively characterized bone marrow-derived BMSCs and HSPCs by using colonyforming efficiency (CFU) assays, differentiation assays, and expression of pluripotency and stem cell genes and proteins that were comparable with embryonic stem cell lines as well as with bonafide MSCs (8). In this study, we investigated the role of low oxidative stress in modulation of the antioxidant defense system in BMSCs and HSPCs. Our results depicted that low $(10 \mu M)$ but not high $(100 \mu M)$ concentrations of $\mathrm{H}_{2} \mathrm{O}_{2}$-induced oxidative stress significantly increased proliferation in BMSCs and HSPCs. Equimolar concentration of Vit. C and its metabolized product, dehydroascorbate (DHA) could revert the molecular and cellular changes caused by $10 \mu \mathrm{M} \mathrm{H}_{2} \mathrm{O}_{2}$. Further mechanistically, an activation of the JNKFOXO3a signaling pathway along with antioxidant-catalase expression and activity was observed in these cells when exposed to $10 \mu M \mathrm{H}_{2} \mathrm{O}_{2}$. Finally, GFP-expressing BMSCs or HSPCs preconditioned with $10 \mu M \mathrm{H}_{2} \mathrm{O}_{2}$ when transplanted at the wound site in vivo resulted in improved engraftment, increased proliferation and catalase expression with a concomitant reduction in ROS along with enhanced keratinocyte formation and vascularization-mediated tissue regeneration.

\section{Results}

\section{Low oxidative stress promotes proliferation of BMSCs and HSPCs}

To evaluate the growth pattern of BMSCs and HSPCs in the presence of $\mathrm{H}_{2} \mathrm{O}_{2}$, the cells were treated for a maximum period of $96 \mathrm{~h}$ as previously described (11). Cells were harvested at a regular interval, and cell count was determined. Both BMSCs (Fig. 1A) and HSPCs (Fig. 1B) depicted a noticeable increase in cell growth, with a reduction in doubling time to $48 \mathrm{~h}$ when treated with $10 \mu M \mathrm{H}_{2} \mathrm{O}_{2}$ as compared with their respective controls ( $\geq 96 \mathrm{~h}$ ). At higher concentrations of $\mathrm{H}_{2} \mathrm{O}_{2}(100 \mu M)$, growth rates of both BMSCs (Fig. 1A) and HSPCs (Fig. 1B) were markedly decreased. Vit. C or DHA at an equimolar concentration could revert the low $\mathrm{H}_{2} \mathrm{O}_{2}$-induced increased growth rate of both BMSCs (Fig. 1A) and HSPCs (Fig. 1B). Further to corroborate the growth pattern of BMSC and HSPC, CFU and bromodeoxyuridine (BrdU) cell proliferation assays were performed. As observed in growth curve kinetics of $10 \mu M$ but not $100 \mu M$ concentration of $\mathrm{H}_{2} \mathrm{O}_{2}$, a significant increase in CFU and BrdU incorporation was depicted in both BMSCs (Fig. 1C, E) and HSPCs (Fig. 1D, 1). Equimolar concentration $(10 \mu M)$ of Vit. C or DHA could rescue the effect of $\mathrm{H}_{2} \mathrm{O}_{2}$. These results clearly suggest that the specificity of $\mathrm{H}_{2} \mathrm{O}_{2}$-mediated oxidative stress promotes the proliferative potential of BMSCs and HSPCs that could be perturbed by the exogenous supplementation of antioxidants.

\section{Low oxidative stress promotes cell cycle progression in BMSCs and HSPCs}

The earlier observation of $10 \mu M \mathrm{H}_{2} \mathrm{O}_{2}$-induced proliferation incited us to explore the cell cycle status of these sorted bone marrow cell populations. Ten micromolar $\mathrm{H}_{2} \mathrm{O}_{2}$ significantly increased cell populations in $S$ and $G_{2} / M$ phases of the cell cycle that was perturbed in the presence of Vit. C (Supplementary Fig. S1A; Supplementary Data are available online at www.liebertpub.com/ars). To substantiate the cell cycle status, we investigated the changes in cell cycle gene expression in BMSCs and HSPCs. Expression of cyclins B1, D2, and E1 was increased by several folds with $10 \mu M \mathrm{H}_{2} \mathrm{O}_{2}$ that was attenuated by an equimolar concentration of Vit. C (Supplementary Fig. S1B). In addition, $10 \mu M \mathrm{H}_{2} \mathrm{O}_{2}$-dependent decrease in expression of p16 and p27 cyclin-dependent kinase inhibitors $(\mathrm{CKI})$ and an increase in proliferating cell nuclear antigen (PCNA) expression were observed, indicating the cell passage through $\mathrm{S}-\mathrm{G}_{2} / \mathrm{M}$ phases of the cell cycle (Supplementary Fig. S1C). The overall increase in cyclins, PCNA, and decrease in CKI expression by $10 \mu M \mathrm{H}_{2} \mathrm{O}_{2}$ promote the bone marrow-derived BMSCs and HSPCs to undergo cell expansion, which otherwise remains in the $G_{0} / G_{1}$ phase of the cell 
A

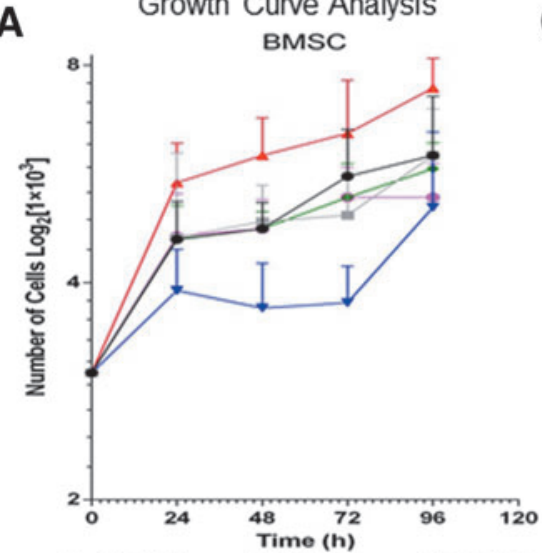

- Control $=1 \mu \mathrm{MH} \mathrm{H}_{2} \mathrm{O}_{2}-10 \mu \mathrm{M} \mathrm{H}_{2} \mathrm{O}_{2}$ $\rightarrow 100 \mu \mathrm{M} \mathrm{H}_{2} \mathrm{O}_{2} \rightarrow 10 \mu \mathrm{M} \mathrm{H} \mathrm{H}_{2} \mathrm{O}_{2}+10 \mu \mathrm{M} \mathrm{DHA}$

B

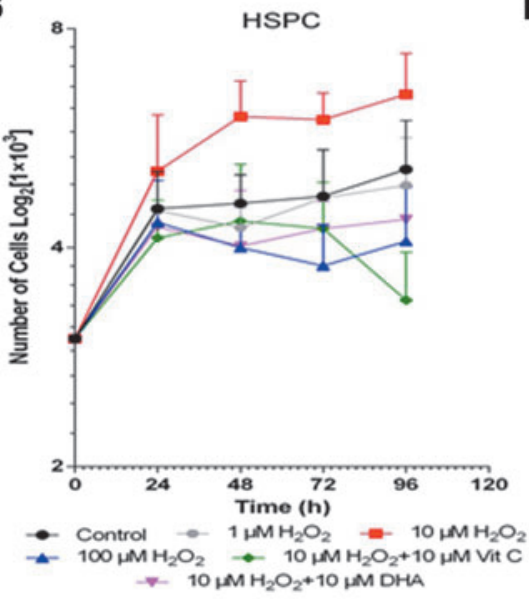

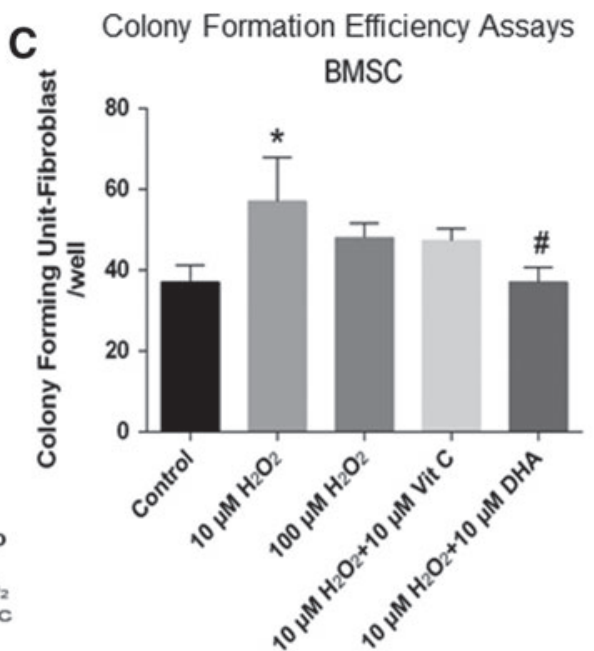

D

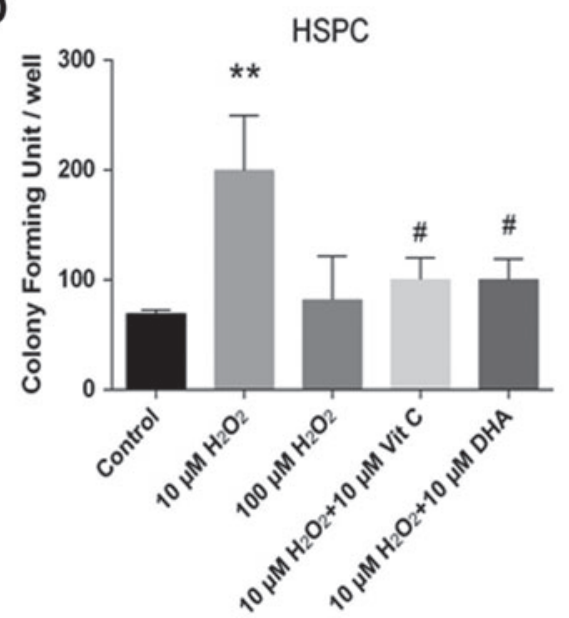

E BrdU Cell Proliferation Assays

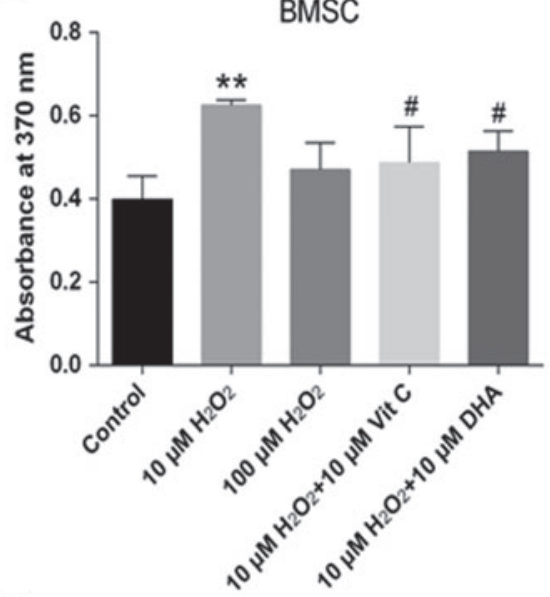

$\mathbf{F}$

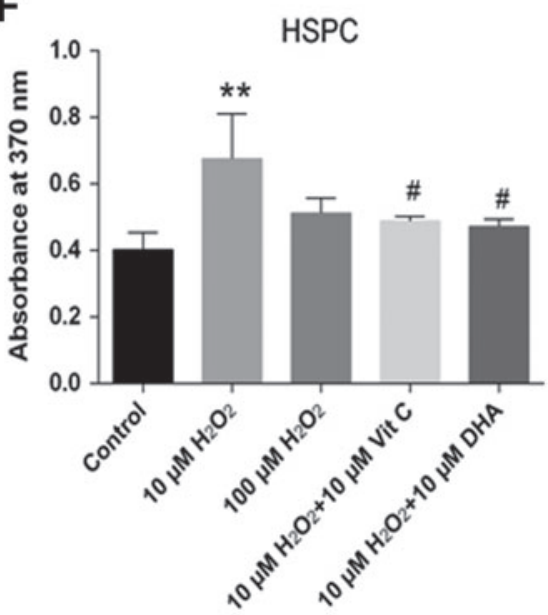

FIG. 1. Low concentration of $\mathrm{H}_{2} \mathrm{O}_{2}$ induces proliferation of BMSCs and HSPCs. Significant increase in cell growth was observed in both bone marrow-derived BMSCs (A) and HSPCs (B) as depicted by growth curve analysis. Antioxidant effects of Vit. $\mathrm{C}$ or DHA could significantly reduce the $\mathrm{H}_{2} \mathrm{O}_{2}$-induced growth rate of BMSCs and HSPCs at $10 \mu M$ concentration. Similar increase in $\mathrm{H}_{2} \mathrm{O}_{2}$-induced colony formation units was observed in BMSCs (C) and HSPCs (D) that was perturbed by exogenous Vit. $\mathrm{C}$ or DHA in colony formation assay. Ten micromolar $\mathrm{H}_{2} \mathrm{O}_{2}$-induced cell proliferation was also observed in BMSCs (E) and HSPCs (F) that was reversed by Vit. C and DHA in BrdU cell proliferation assay. Results are depicted as percent proliferation of control $(n=4$ 6 replicates per isolation; $p<0.05$ as compared with $*$ control and ${ }^{\#} 10 \mu M \mathrm{H}_{2} \mathrm{O}_{2}$-treated group; $p<0.01$ as compared with $* *$ control). BMSC, bone marrow stromal stem/progenitor cells; BrdU, bromodeoxyuridine; DHA, dehydroascorbic acid; $\mathrm{H}_{2} \mathrm{O}_{2}$, hydrogen peroxide; HSPC, hematopoietic stem and progenitor cells; Vit. C, vitamin C. To see this illustration in color, the reader is referred to the web version of this article at www.liebertpub.com/ars

cycle. The mechanism of this cellular effect by oxidative stress was further supported by the ROS quencher-induced reversal of specific cell cycle gene induction.

\section{Cellular redox status in $\mathrm{H}_{2} \mathrm{O}_{2}$-treated BMSCs and HSPCs}

To evaluate the intracellular and extracellular ROS levels along with glutathione (GSH) content in sorted BMSCs and HSPCs exposed to $\mathrm{H}_{2} \mathrm{O}_{2}$, DCFH-DA staining, amplex red assay, and glutathione assay were performed. Significantly high concentration-dependent intracellular ROS levels were observed after 24 and $48 \mathrm{~h}$ post-treatment of $\mathrm{H}_{2} \mathrm{O}_{2}$ in BMSCs (Supplementary Fig. S2A) and HSPCs (Supplementary Fig. S2B) that was attenuated by Vit. C or DHA. The extracellular ROS level $\left(\mathrm{H}_{2} \mathrm{O}_{2}\right.$ concentration) depicted a concentration-dependent significant increase that was overturned by addition of Vit. $\mathrm{C}$ or DHA as compared with control at $24 \mathrm{~h}$. Further at $48 \mathrm{~h}$ post- treatment, the extracellular ROS level decreased and was comparable to the control group, indicating the utilization of $\mathrm{H}_{2} \mathrm{O}_{2}$ by BMSCs (Supplementary Fig. S2C) and HSPCs (Supplementary Fig. S2D). In line with the $\mathrm{H}_{2} \mathrm{O}_{2}$-induced increased ROS production, a concentration-dependent significant decrease of cellular GSH content was restored in BMSCs (Supplementary Fig. S2E) and HSPCs (Supplementary Fig. S2F) by addition of Vit. C or DHA as compared with the control at $48 \mathrm{~h}$ posttreatment. These data suggest that even $10 \mu M \mathrm{H}_{2} \mathrm{O}_{2}$ causes significant oxidant perturbation in BMSCs and HSPCs that can, subsequently, activate downstream signal transduction pathways.

\section{Low oxidative stress-induced activation of molecular signal transduction pathways in BMSCs and HSPCs}

We evaluated the role of oxidative stress on growth-promoting and proliferative signal transduction pathways in BMSCs and HSPCs using immunoblot analysis. Ten micromolar $\mathrm{H}_{2} \mathrm{O}_{2}$ 
A

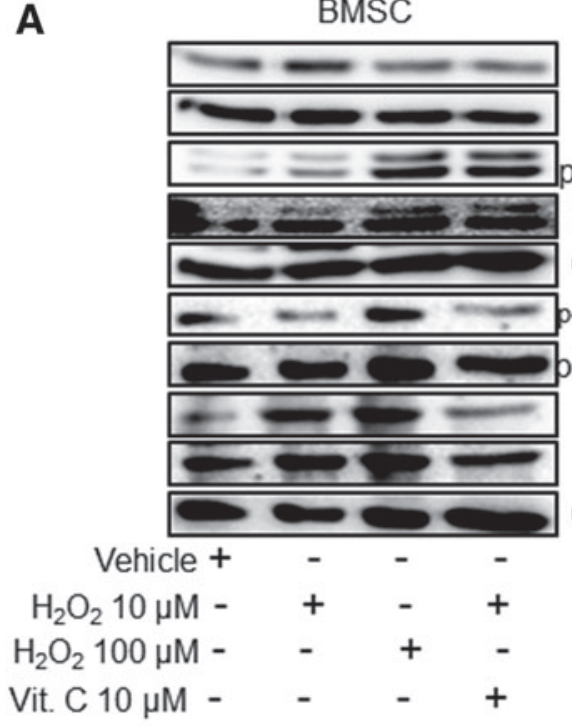

D

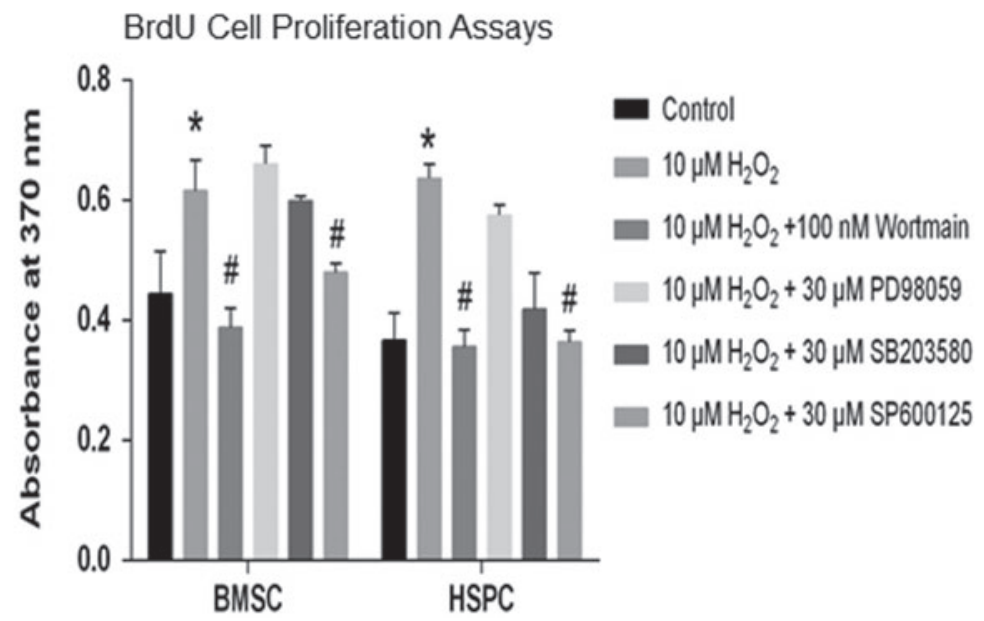

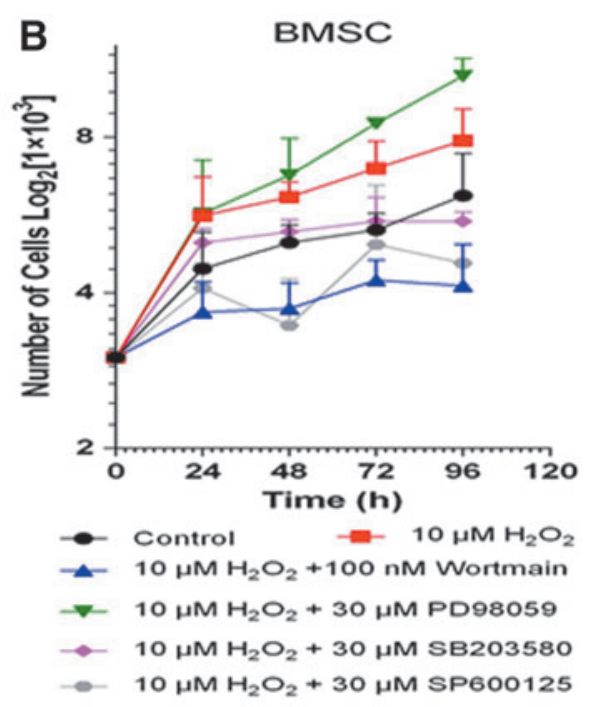

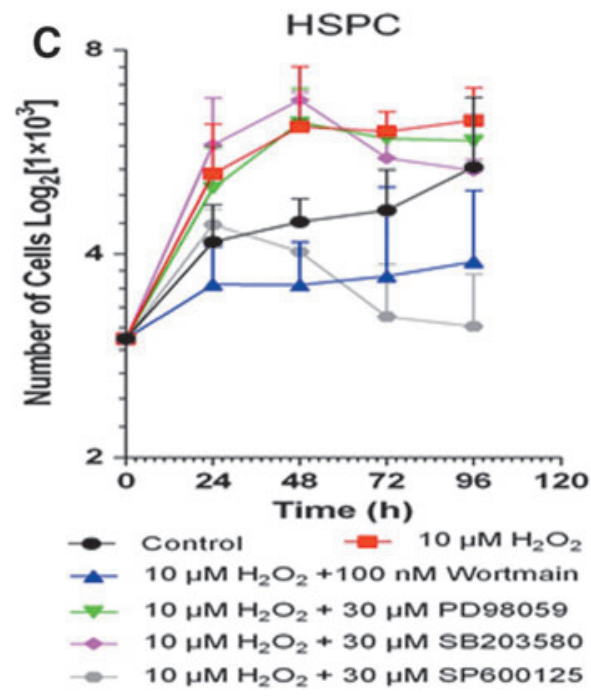

FIG. 2. Role of AKT and JNK activation on $\mathrm{H}_{2} \mathrm{O}_{2}$-induced BMSC and HSPCs proliferation. (A) Expression levels of phosphorylated and total protein levels of AKT, ERK1/2, p38 MAPK, and JNK were determined by Western blot analysis. Ten micromolar $\mathrm{H}_{2} \mathrm{O}_{2}$-induced AKT and JNK activation (phosphorylation) that was reverted by $10 \mu M$ Vit. C in both BMSCs and HSPCs. Growth curve analysis of cells exposed to $10 \mu M \mathrm{H}_{2} \mathrm{O}_{2}$ along with pathway inhibitors in BMSCs (B) and HSPCs (C) depicted a decreased growth rate in the presence of wortmannin (AKT inhibitor) and SP600125 (JNK inhibitor) treatment. PD98059 (ERK1/2 inhibitor) and SB23058 (p38 MAPK inhibitor) did not reduce the $10 \mu M \mathrm{H}_{2} \mathrm{O}_{2}-$ induced growth rate of both BMSCs and HSPCs. (D) BrdU cell proliferation assay depicted a significant decrease in BrdU incorporation in both BMSCs and HSPCs exposed to $10 \mu M \mathrm{H}_{2} \mathrm{O}_{2}$ along with wortmannin and SP600125, suggesting a pathway specificity ( $n=4-6$ replicates per isolation; $p<0.05$ as compared with *control and ${ }^{\#} 10 \mu M \mathrm{H}_{2} \mathrm{O}_{2}$-treated group). $\mathrm{JNK}$, c-Jun $\mathrm{N}$ terminal kinase. To see this illustration in color, the reader is referred to the web version of this article at www.liebertpub.com/ars

treatment in these cells led to an increased phosphorylation of AKT and JNK (Fig. 2A). Further, a sub-lethal or high concentration of $\mathrm{H}_{2} \mathrm{O}_{2}(100 \mu M)$ could phosphorylate JNK but not AKT, indicating a selective activation of JNK stress kinase (Fig. 2A), which was further confirmed by densitometric analysis (BMSCsSupplementary Fig. S3A and HSPCs-Supplementary Fig. S3B). In addition, activation of ERK1/2 and p38 MAPK under similar conditions yielded insignificant change of these signaling mediators in both BMSCs and HSPCs. To confirm whether the earlier observation holds true, we treated HSPCs and BMSCs with $\mathrm{H}_{2} \mathrm{O}_{2}$ in both the presence and absence of inhibitors such as Wortmannin (AKT), SP600125 (JNK), PD98059 (ERK1/2) (48), and SB203580 (p38 MAPK) (12). Indeed, wortmannin and
SP600125 at $100 \mathrm{n} M$ and $30 \mu M$, respectively, could significantly decrease the $\mathrm{H}_{2} \mathrm{O}_{2}$-induced proliferation in BMSCs (Fig. 2B) as well as HSPCs (Fig. 2C) as observed in both growth curve analysis and BrdU cell proliferation assays (Fig. 2D), suggesting pathway specificity. These observations indicate that $10 \mu M$ $\mathrm{H}_{2} \mathrm{O}_{2}$-induced proliferation is mediated by concerted action of both AKT and JNK signaling pathways.

\section{Cellular antioxidants facilitate BMSC and HSPC proliferation at low oxidative stress}

Further, we investigated the status of the redox genes that are essential to detoxify the $\mathrm{H}_{2} \mathrm{O}_{2}$ as well as its effect on the 
downstream cell signaling. Among the different isoforms of mammalian SODs, an $\mathrm{H}_{2} \mathrm{O}_{2}$-mediated concentrationdependent increase in the expression of SOD2, the mitochondrial isoform was observed in both BMSC and HSPC populations, which were decreased by an equimolar concentration of Vit. C (Supplementary Fig. S4A). Similarly, the expression of GPx2 (mitochondrial isoform of GPx) depicted a 2.9-fold high in both BMSCs and HSPCs as compared with the control in the presence of $\mathrm{H}_{2} \mathrm{O}_{2}$, which was not abrogated by an equimolar concentration of Vit. C (Supplementary Fig. S4B). Expression of catalase was 3.75-fold higher in BMSCs and 3.9-fold higher in HSPCs than the respective control at $10 \mu \mathrm{M}$ exposure of $\mathrm{H}_{2} \mathrm{O}_{2}$, which was mitigated in the presence of an equimolar concentration of Vit. C, indicating that low oxidative stress induces its expression
(Fig. 3A). However, at sub-lethal $\mathrm{H}_{2} \mathrm{O}_{2}$ concentration, catalase expression was decreased in both BMSCs and HSPCs, which substantiates with the existing literature that $\mathrm{H}_{2} \mathrm{O}_{2}$ at a high concentration downregulates catalase expression by epigenetic regulation via methylation of $\mathrm{CpG}$ islands (35).

Further, in parallel with their transcript levels, we also evaluated the activity of these antioxidant enzymes SOD, GPx, and catalase in cell extracts. Although a concentrationdependent increase in activity of SOD was observed in HSPCs and BMSCs treated with $\mathrm{H}_{2} \mathrm{O}_{2}$, an equimolar concentration of Vit. $\mathrm{C}$ could not reverse the $\mathrm{H}_{2} \mathrm{O}_{2}$-induced increase in total SOD activity (Supplementary Fig. S4C). Similarly, total GPx activity depicted an insignificant change in BMSCs (Supplementary Fig. S4D) but in HSPCs a significant increase was observed only at a high concentration $(100 \mu M)$ of $\mathrm{H}_{2} \mathrm{O}_{2}$
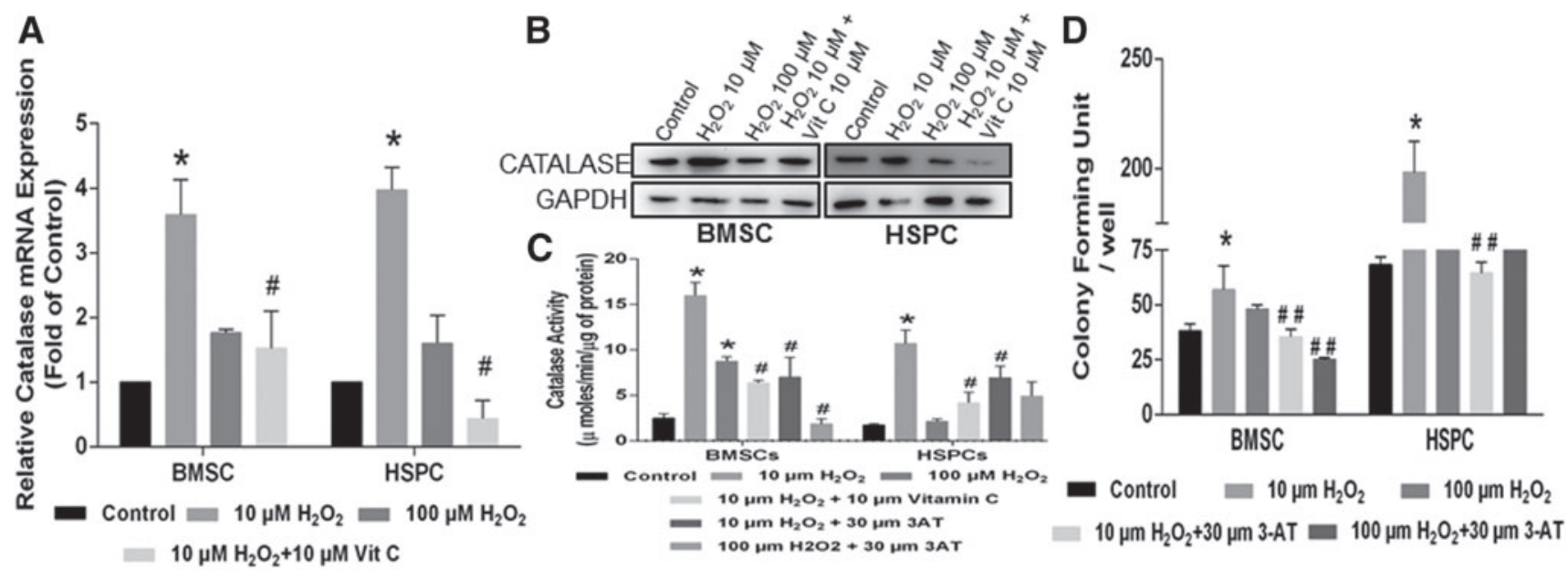

E

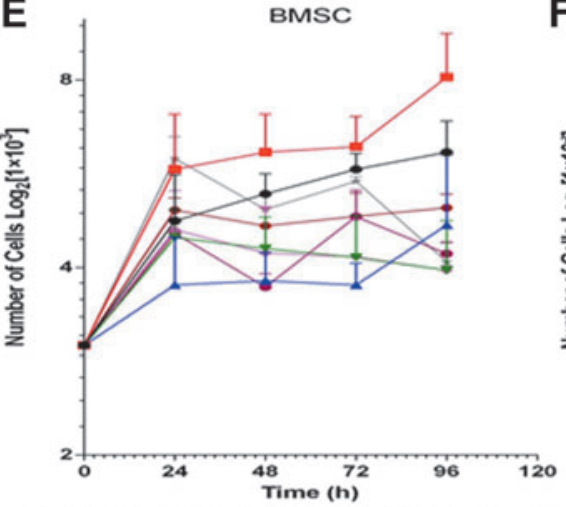

- Control $=10 \mu \mathrm{M} \mathrm{H}_{2} \mathrm{O}_{2} \neq 100 \mu \mathrm{MH}_{2} \mathrm{O}_{2}+$

- $10 \mu \mathrm{M} \mathrm{H}_{2} \mathrm{O}_{2}+$ PEG-Catalase $* 100 \mu \mathrm{M} \mathrm{H}_{2} \mathrm{O}_{2}+$ PEG-Catalase
$\mathbf{F}$

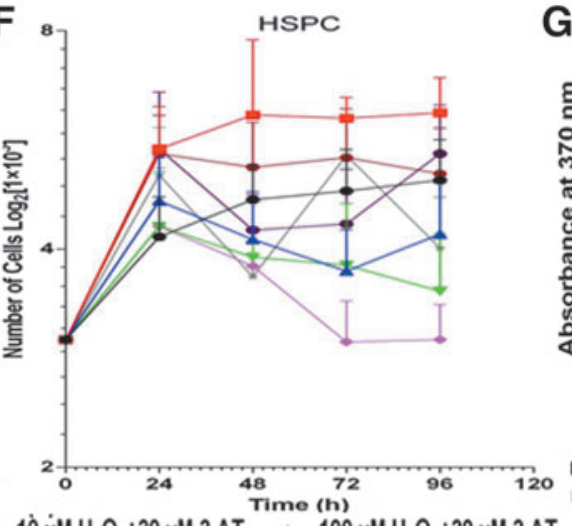

$10 \mu \mathrm{M} \mathrm{H}_{2} \mathrm{O}_{2}+30 \mu \mathrm{M} 3-\mathrm{AT}+\mathrm{PEG}$-Catalase

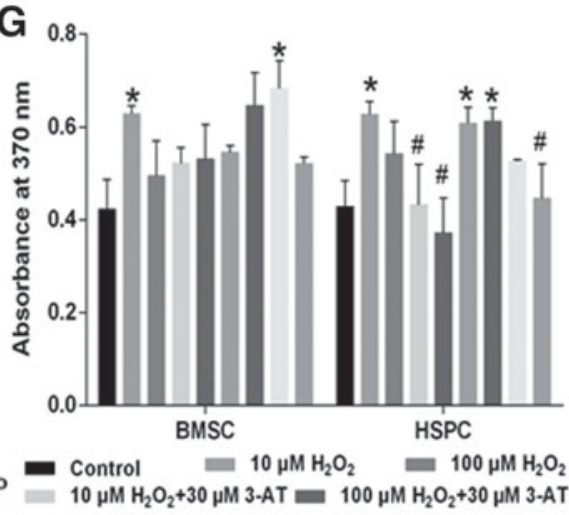

$=10 \mu \mathrm{M} \mathrm{H}_{2} \mathrm{O}_{2}+$ PEG-Catalase

$=10 \mu \mathrm{M} \mathrm{H}_{2} \mathrm{O}_{2}+30 \mu \mathrm{M}$ 3-AT+PEG-Catalase

$10 \mu \mathrm{M} \mathrm{H}_{2} \mathrm{O}_{2}+\mathrm{Scr}$ siRNA $=10 \mu \mathrm{M} \mathrm{H}_{2} \mathrm{O}_{2}+$ Catalase siRNA

FIG. 3. Low concentration of $\mathrm{H}_{2} \mathrm{O}_{2}$ potentiates the expression of antioxidant catalase, which when inhibited reversed $\mathrm{H}_{2} \mathrm{O}_{2}$-induced proliferative effect on BMSCs and HSCs. $10 \mu M$ concentration of $\mathrm{H}_{2} \mathrm{O}_{2}$ induced catalase mRNA (A) and protein (B) expression, whereas a high concentration did not. (C) Biochemical enzyme activity of catalase was evaluated in BMSCs and HSPCs treated with $\mathrm{H}_{2} \mathrm{O}_{2}$, Vit. C, and 3-AT. Catalase activity was significantly high in cells treated with $10 \mu M \mathrm{H}_{2} \mathrm{O}_{2}$. Vit. $\mathrm{C}$ at an equimolar low concentration $(10 \mu M)$ and 3-AT, a catalase inhibitor $(30 \mu M)$, significantly reversed the $\mathrm{H}_{2} \mathrm{O}_{2}$-induced catalase activity in these cell populations. A further increase to $100 \mu M \mathrm{H}_{2} \mathrm{O}_{2}$ decreased the catalase activity. (D) Similarly, a decrease in $\mathrm{H}_{2} \mathrm{O}_{2}$-induced colony-forming efficiency was observed in the presence of 3-AT. Next, $\mathrm{H}_{2} \mathrm{O}_{2}$-induced growth pattern of BMSCs (E) and HSPCs (F) in the presence of 3-AT depicted a decrease in growth rate. Further addition of PEG-catalase reversed the inhibition shown by 3-AT treatment. (G) Addition of 3-AT attenuated low $\mathrm{H}_{2} \mathrm{O}_{2}$-induced BrdU cellular incorporation in BMSCs and HSPCs. Addition of PEG catalase reversed the inhibitory effect imparted by 3-AT. Further, siRNA-CAT (siRNA against catalase gene) transfected BMSCs and HSPCs depicted a significant decrease in BrdU incorporation ( $n=3-6$ replicates per isolation; $p<0.05$ as compared with $*$ control and ${ }^{\#} 10 \mu M \mathrm{H}_{2} \mathrm{O}_{2}$-treated group). 3-AT, 3 Amino-triazole. To see this illustration in color, the reader is referred to the web version of this article at www.liebertpub.com/ars 
(Supplementary Fig. S4D). Increased expression of catalase translated equally with increased protein expression (Fig. 3B) and increased biochemical activity at $10 \mu M \mathrm{H}_{2} \mathrm{O}_{2}$ that was reversed by exogenous antioxidants in BMSCs and HSPCs (Fig. 3C). These observations clearly indicate the role of the antioxidant enzyme, catalase in regulating the oxidative stress caused due to $10 \mu M \mathrm{H}_{2} \mathrm{O}_{2}$ in BMSCs and HSPCs, thereby modulating cellular proliferation.

\section{Catalase inhibition sensitizes BMSCs and HSPCs to low oxidative stress}

To further investigate the role of catalase in low oxidative stress-induced cell proliferation, a pharmacological inhibitor of catalase, 3-Aminotriazole (3-AT) was used (41). A low concentration of $\mathrm{H}_{2} \mathrm{O}_{2}$-stimulated cell proliferation was sig- nificantly decreased by 3 -AT $(30 \mu M)$, as depicted by a decrease in the percent cell population in $S-G_{2} / M$ phase of the cell cycle (Supplementary Fig. S5A). At a biochemical level, catalase enzyme activity was also observed to be significantly decreased in BMSCs and HSPCs treated with $10 \mu M \mathrm{H}_{2} \mathrm{O}_{2}$ and 3-AT (Fig. 3C). Next, colony formation (Fig. 3D) and growth curve assays also depicted a decrease in cell number when treated with $10 \mu M \mathrm{H}_{2} \mathrm{O}_{2}$ in combination with $30 \mu M$ 3-AT in both BMSC (Fig. 3E) and HSPC (Fig. 3F). A similar outcome was observed in BrdU cell proliferation assay (Fig. 3G), although 3-AT treatment alone did not depict any significant difference in cell proliferation (Supplementary Fig. S5B). The pharmacologic administration of PEG catalase rescued the inhibitory effect on cell proliferation imparted by 3-AT (Fig. 3E-G). Catalase siRNA transfection of both BMSCs and HSPCs resulting in gene silencing
A

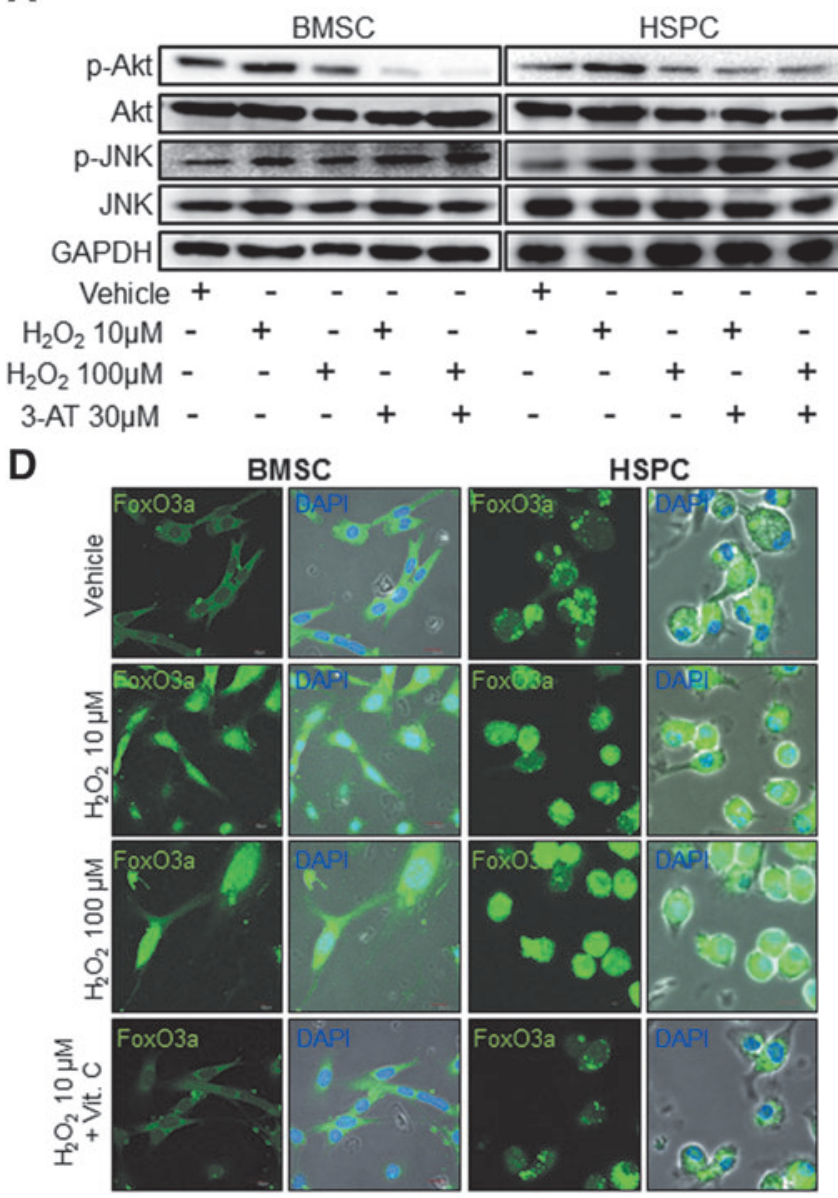

B
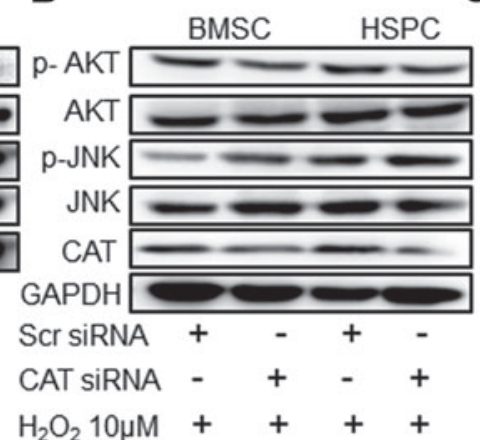

BMSC

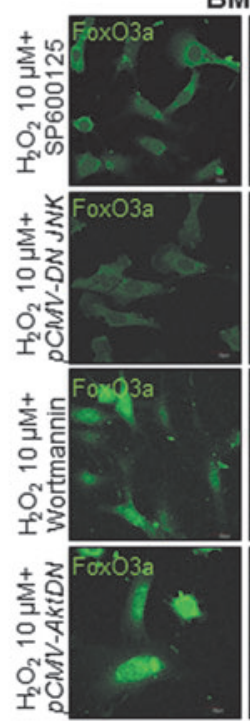

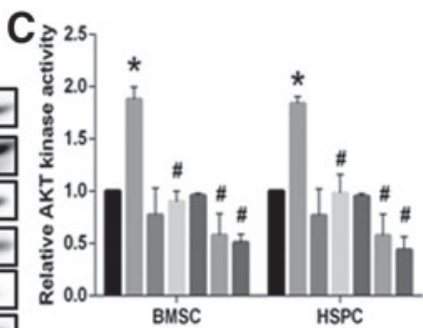

- Control $=10 \mu \mathrm{M} \mathrm{H} \mathrm{O}_{2}=100 \mu \mathrm{M} \mathrm{\textrm {O } _ { 2 } \mathrm { O } _ { 2 }}$ $10 \mu \mathrm{M} \mathrm{H} \mathrm{H}_{2}+30 \mu \mathrm{M} 3 \mathrm{AT}$ - $100 \mu \mathrm{M} \mathrm{H}_{2} \mathrm{O}_{2}, 30 \mu \mathrm{M} 3-\mathrm{AT}$

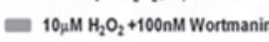
- $10, \mu \mathrm{M} \mathrm{H} \mathrm{O}_{2} \mathrm{O}_{2}+30 \mu \mathrm{M} S \mathrm{PP} 600125$ HSPC

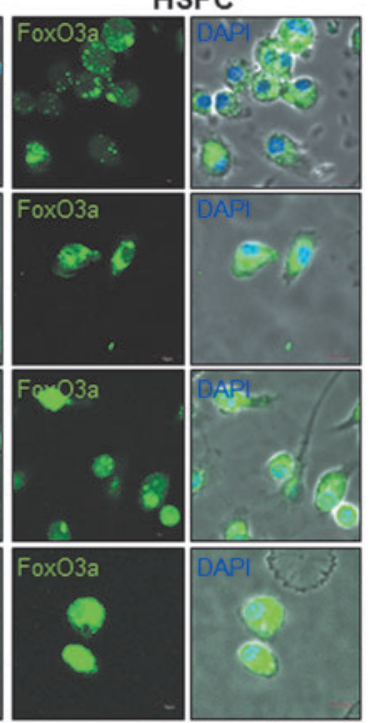

FIG. 4. Low concentration of $\mathrm{H}_{2} \mathrm{O}_{2}$ led to an increased JNK activation and FOXO3a nuclear translocation. (A) Western blot analysis revealed that $10 \mu M \mathrm{H}_{2} \mathrm{O}_{2}$-induced AKT activation was reverted by addition of 3-AT. On the contrary, catalase inhibition led to insignificant change in JNK phosphorylation. (B) Silencing the catalase at molecular level by using CAT siRNA transfection depicted similar results as 3-AT. (C) $10 \mu M \mathrm{H}_{2} \mathrm{O}_{2}$-induced AKT kinase activity was inhibited in the presence of inhibition of catalase (3-AT) or JNK (SP600125) or positive control AKT (wortmannin) in both BMSCs and HSPCs. (D) A dose-dependent increase in $\mathrm{H}_{2} \mathrm{O}_{2}$-mediated FOXO3a nuclear translocation was abrogated in the presence of Vit. $\mathrm{C}$ that sequestered FOXO3a in the cytoplasm. Pharmacological (SP600125) as well as molecular ( $p C M V$ $D N J N K$ ) inhibition of JNK prevented FOXO3a nuclear translocation, whereas AKT inhibition using wortmannin or $p C M V$ $A k t D N$ retained FOXO3a into the nucleus. Cells were stained with anti-FOXO3a rabbit polyclonal antibody followed by addition of AlexaFluor 488-labeled anti-rabbit secondary antibody. Nuclei were stained with DAPI. Quantification of nuclear localization along with Western blot images was evaluated by using NIH Image J software. CAT, catalase; DAPI, 4',6-diamidino-2-phenylindole; FOXO3a, forkhead box O3a. To see this illustration in color, the reader is referred to the web version of this article at www.liebertpub.com/ars 
(Supplementary Fig. S5C) led to a decrease in $10 \mu M \mathrm{H}_{2} \mathrm{O}_{2}$ induced cell proliferation (Fig. 3G). These results clearly suggest that an increased cell cycle progression and expansion of BMSCs and HSPCs in the presence of $10 \mu M \mathrm{H}_{2} \mathrm{O}_{2}$ but not at higher $100 \mu M \mathrm{H}_{2} \mathrm{O}_{2}$ is correlated with increased catalase expression and activity.

To determine the effects of catalase inhibition on proliferative signaling mechanisms of AKT and JNK activation, we treated both BMSCs and HSPCs with 3-AT in the presence/absence of $10 \mu M$ or $100 \mu M$ concentration of $\mathrm{H}_{2} \mathrm{O}_{2}$. Catalase inhibition in these cell types depicted a downregulation of the AKT but not JNK signaling pathway (Fig. 4A), as evident from the densitometric analysis (Supplementary Fig. S5D). This observation suggests that in the absence of active catalase, even $10 \mu M$ concentration of $\mathrm{H}_{2} \mathrm{O}_{2}$ sensitizes the cells by inducing JNK stress kinases alike a sub-lethal $(100 \mu M)$ concentration of $\mathrm{H}_{2} \mathrm{O}_{2}$ (Supplementary Fig. S5D). Similarly, decreased AKT activation whereas increased JNK activation was observed with silencing of catalase using CAT-siRNA at molecular level (Fig. 4B) and densitometric analysis or repeated blots (Supplementary Fig. S5E). To confirm AKT activation only at $10 \mu M \mathrm{H}_{2} \mathrm{O}_{2}$ in both BMSC and HSPC with active catalase, we evaluated the AKT kinase activity in the presence/absence of 3-AT (10). Significantly high AKT kinase activity was observed in the presence of $10 \mu M \mathrm{H}_{2} \mathrm{O}_{2}$ that was inhibited by 3-AT or wortmannin (positive control) (Fig. 4C). Interestingly, JNK inhibition also decreased AKT activation, indicating an existence of signaling crosstalk (Fig. 4C). Further, at molecular level, JNK (23) and AKT (47) dominant negative (DN) mutants could also decrease the $10 \mu M \mathrm{H}_{2} \mathrm{O}_{2}$-induced AKT activity (Supplementary Fig. S6A). Next, we evaluated the levels of intracellular ROS in the presence of catalase inhibition. Significantly similar high intracellular ROS levels were observed in both BMSC (Supplementary Fig. S6B) and HSPC (Supplementary Fig. S6C) treated with $10 \mu M$ or $100 \mu M \mathrm{H}_{2} \mathrm{O}_{2}$ along with 3-AT administration, suggesting an increased ROS-mediated AKT inactivation. Ten micromolar $\mathrm{H}_{2} \mathrm{O}_{2}$-induced increased AKT activation (phosphorylation) was perturbed by molecular inhibition using AKT and JNK DN mutants in both BMSC (Supplementary Fig. S6D) and HSPC (Supplementary Fig. S6E) along with cell proliferation (Supplementary Fig. S6F). Interestingly, molecular inhibition of JNK also led to decreased cell proliferation, indicating its involvement via catalase downregulation-mediated effect.

\section{FOXO3a nuclear translocation induces transcriptional upregulation of catalase at low oxidative stress}

In the JNK stress signaling cascade, activated JNK is known to translocate FOXO3a, a transcription factor to the nucleus for transcriptional upregulation of FOXO3a target genes (25). Therefore, we determined the concentrationdependent effect of $\mathrm{H}_{2} \mathrm{O}_{2}$-induced activation of JNK on FOXO3a nuclear translocation. As expected, $10 \mu M$ and $100 \mu M \mathrm{H}_{2} \mathrm{O}_{2}$ depicted a concentration-induced nuclear translocation of FOXO3a (Fig. 4D and Supplementary Fig. S7A-C) whereas Vit. C led to FOXO3a retention in the cytoplasm (Fig. 4D, Supplementary Fig. S7A). Pharmacological (Fig. 4D and Supplementary Fig. S7A) as well as molecular (Fig. 4D and Supplementary Fig. S7A-C) inhibition of JNK inhibited the nuclear translocation of FOXO3a, whereas a similar inhibition of AKT did not have any effect on FOXO3a nuclear translocation (Fig. 4D and Supplementary Fig. S7A-C). Although activation of AKT is known to impart an inhibitory effect on FOXO3a nuclear translocation, recent studies suggest that a simultaneous JNK activation overrides AKT signaling, thereby dominating the FOXO3a nuclear translocation (4). Our results too clearly suggest the mechanism of $\mathrm{H}_{2} \mathrm{O}_{2}$-induced oxidative stress-mediated JNK activation, which, in turn, leads to nuclear translocation of FOXO3a that acts as a transcriptional co-regulator of its target gene expression. In our in silico analysis (data not shown) as well as other studies, an FOXO3a binding site is suggested in the promoter region of catalase gene (39). To further confirm this, we evaluated the catalase promoter that contained three potential FOXO3a binding sites: one at a distal region, distal binding site (DBS) and two others at a proximal region, proximal binding site (PBS1 and PBS2) (Fig. 5A). Chromatin immunoprecipitation (ChIP) analysis revealed that at $10 \mu M \mathrm{H}_{2} \mathrm{O}_{2}$ concentration, FOXO3a binds with a relatively higher affinity to catalase promoter at DBS in HSPCs as compared with BMSCs (Fig. 5B). However, a differential binding of FOXO3a to the PBS1 and PBS2 on catalase promoter was observed at $10 \mu M \mathrm{H}_{2} \mathrm{O}_{2}$ concentration. A high binding of FOXO3a to PBS2 in BMSCs (Fig. 5C) and PBS1 in HSPCs (Fig. 5D) was observed. Increased $\mathrm{H}_{2} \mathrm{O}_{2}$ concentration consequently led to decreased $\mathrm{FOXO}$ a binding to catalase promoter (Fig. 5B-D). Vit. C and JNK inhibitor, SP600125 in the presence of $10 \mu M \mathrm{H}_{2} \mathrm{O}_{2}$ concentration, decreased $\mathrm{FOXO}$ a binding to catalase promoter, indicating the $10 \mu M \mathrm{H}_{2} \mathrm{O}_{2}$-mediated transcriptional upregulation of catalase via JNK-FOXO3a signaling. This was further confirmed by a decreased catalase gene expression in the presence of JNK inhibitor (SP600125) but not AKT inhibitor (wortmannin) in $10 \mu M \mathrm{H}_{2} \mathrm{O}_{2}$-treated BMSC and HSPCs (Fig. 5E), suggesting that although $10 \mu M \mathrm{H}_{2} \mathrm{O}_{2}$-induced activation of JNK and AKT was observed in these proliferating cells, only JNK but not AKT imparts a direct regulation on catalase expression. To further substantiate this observation, we evaluated catalase mRNA and protein expression in the presence of JNK and AKT DN mutants. Molecular inhibition of JNK but not AKT led to a decrease in catalase mRNA (Supplementary Fig. S7D) and protein (Supplementary Fig. S7E) expression in $10 \mu M$ $\mathrm{H}_{2} \mathrm{O}_{2}$-treated BMSC and HSPC, which corroborated further with catalase activity (Supplementary Fig. S7F). These results indicate that physiological relevance of AKT activation in $10 \mu M \mathrm{H}_{2} \mathrm{O}_{2}$-treated BMSC and HSPC might have a direct regulation on cell proliferation.

\section{AKT and catalase inhibition downregulates cell proliferation-related genes at low oxidative stress}

AKT inhibition-mediated decreased cell proliferation in $10 \mu M \mathrm{H}_{2} \mathrm{O}_{2}$-treated BMSC and HSPC was confirmed by the observation of decreased expression of cyclins B1, D2, and E2 (Fig. 5F) and PCNA (Fig. 5G) along with concomitant increased expression of CKIs p16 and p27 (Fig. 5G). Molecular inhibition of AKT also led to a decreased expression of cyclins (Supplementary Fig. S7G) and increased expression of CKIs (Supplementary Fig. S7H), thereby confirming the role of AKT in cell proliferation. Interestingly, JNK molecular inhibition indirectly led to a decrease in cyclin expression and an increase in CKIs expression via a decrease in catalase 
A

FOXO3a Binding sites on Catalase promoter

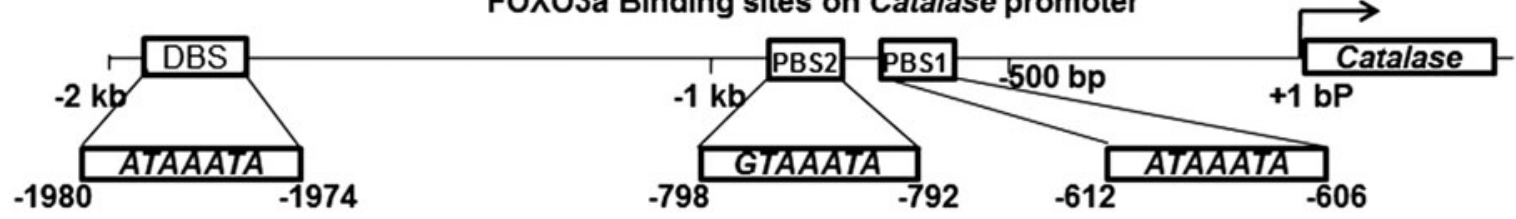

B FOX03a ChIP-DBS Catalase Promoter

C FOX03a ChIP.PBS2 Catalase Promoter

D FOX03a ChIP-PBS1 Catalase Promoter

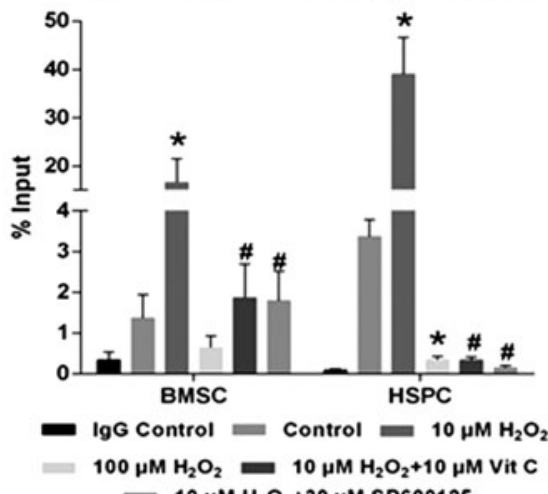

E
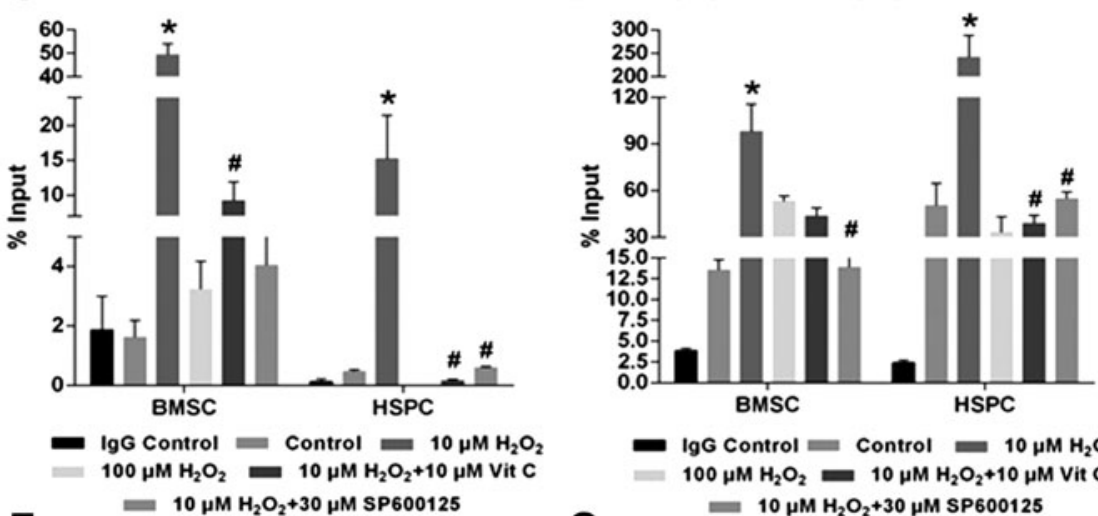

F
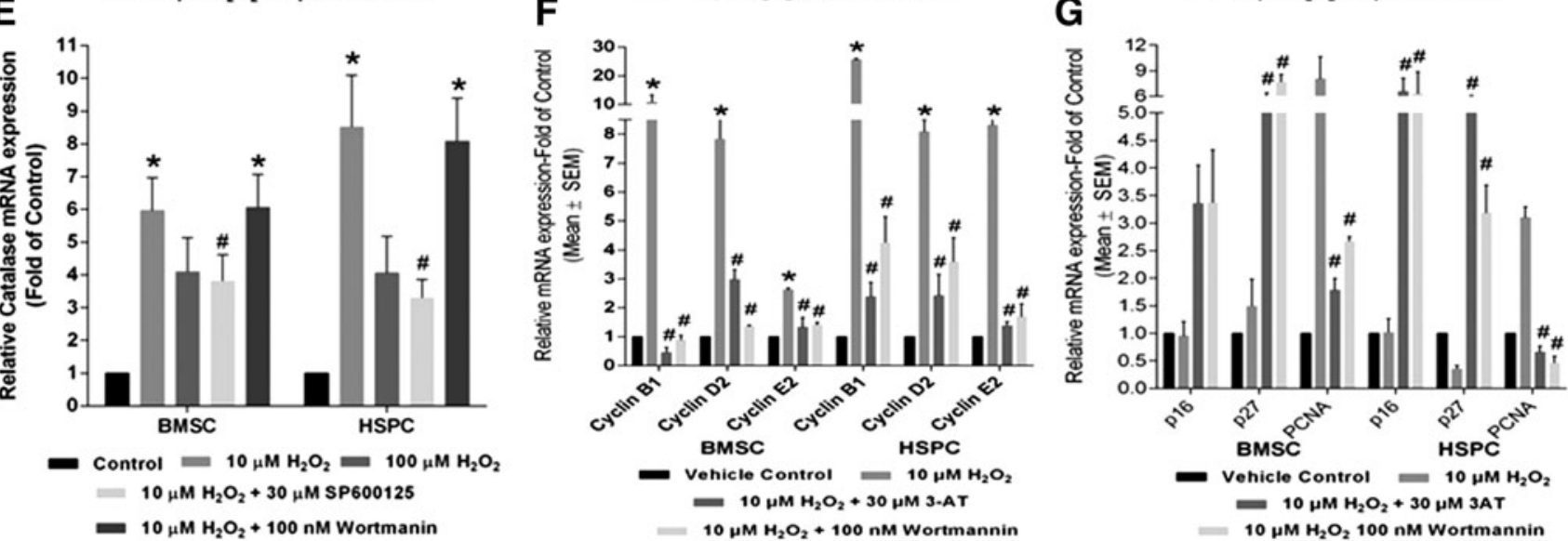

FIG. 5. Low concentration of $\mathrm{H}_{2} \mathrm{O}_{2}$ potentiates FOXO3a binding to catalase promoter. (A) Schematic representation of catalase promoter depicting different FOXO3a binding sites upstream to transcription start site. ChIP analysis depicted an increased binding of FOXO3a on the catalase promoter at the (B) distal binding site (DBS, -1980 to -1974$)$, (C) proximal binding site 2 (PBS2, -798 to -792), and (D) PBS1 (-612 to -606). (E) Low $\mathrm{H}_{2} \mathrm{O}_{2}$-induced catalase mRNA expression was abrogated in the presence of JNK inhibitor, SP600125 but not AKT inhibitor, wortmannin. (F) AKT as well as catalase inhibition significantly decreased the $10 \mu M \mathrm{H}_{2} \mathrm{O}_{2}$-induced cyclins B1, D2, and E2 expression in both BMSCs and HSPCs. (G) $10 \mu \mathrm{M}$ concentration of $\mathrm{H}_{2} \mathrm{O}_{2}$-mediated decreased expression of CKIs, p16, and p27 was markedly reversed by AKT or catalase inhibition ( $n=3$ replicates per isolation; $p<0.05$ as compared with *control; ${ }^{*} 10 \mu M \mathrm{H}_{2} \mathrm{O}_{2}$-treated group).

expression (Supplementary Fig. S7F, G). As observed earlier, downregulation of catalase led to inactivation of AKT; 3-AT treatment also resulted in decreased cyclins (Fig. 5F), PCNA (Fig. 5G) and increased CKIs expression (Fig. 5G), indicating a simultaneous induction of the JNK-FOXO3a-catalase signaling cascade along with AKT-cyclins-cell proliferation in the presence of $10 \mu M \mathrm{H}_{2} \mathrm{O}_{2}$-induced low oxidative stress in $\mathrm{BMSC}$ and $\mathrm{HSPC}$ wherein perturbation of the former signaling regulates the latter.

\section{Low oxidative stress preconditioned BMSCs and HSPCs enhance wound tissue repair}

One of the major causes of poor endurance of stem cells in vivo in an injury microenvironment is the poor expansion of transplanted stem cells. Exposure to low oxidative stress in vitro (preconditioning with $10 \mu M \mathrm{H}_{2} \mathrm{O}_{2}$ ) before transplantation at the wound site was hypothesized to increase the proliferation of BMSCs and HSPCs. Thus, we utilized a murine model of excisional splinting wound as described earlier (9) wherein wounds heal through granulation and reepithelialization, a process similar to that which occurs in humans (43). Mice transplanted with preconditioned BMSCs and HSPCs showed an accelerated wound closure postsurgery day 7 as compared with mice transplanted with naive BMSCs and HSPCs only (Fig. 6A). Further temporal quantification of the regenerated wound area depicted a $75 \%$ wound closure in preconditioned BMSCs as compared with $56 \%$ in naive BMSCs at postsurgery day 7 (Fig. 6B). Similar results were observed with preconditioned HSPCs representing an increased wound closure of $71 \%$ at postsurgery day 7 (Fig. 6B). Histopathological analysis of regenerated 

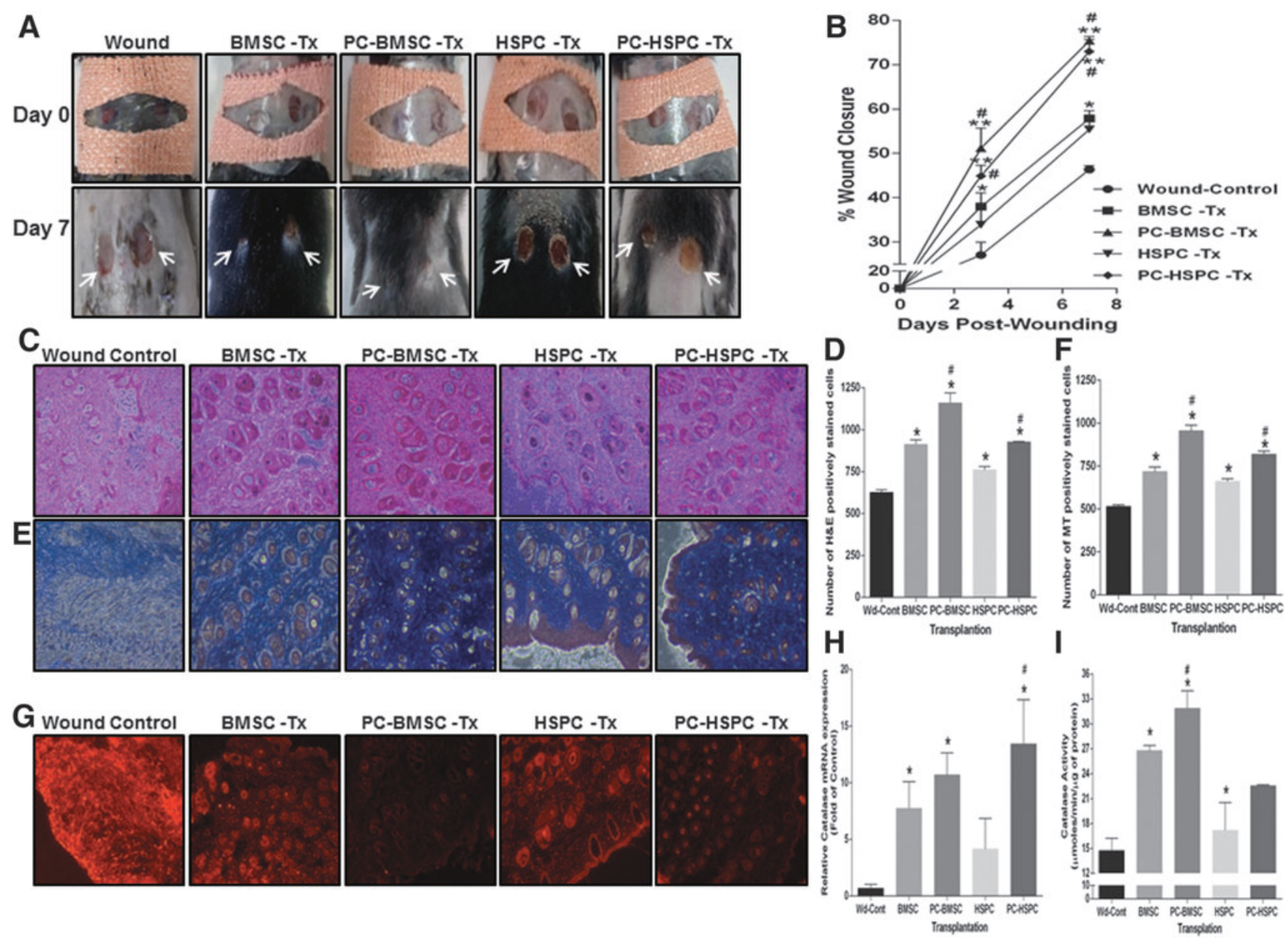

FIG. 6. $10 \mu M \mathrm{H}_{2} \mathrm{O}_{2}$ preconditioned BMSCs or HSPCs transplantation improves wound repair and antioxidant defense system. (A) A representative image of wound healing in $C 57 B L / 6 J$ mouse at postsurgery days 0 (upper panel) and 7 (lower panel). (B) Quantitation of wound area at different time points postwound generation (Days 0,3, and 7) was performed by using NIH image J software. The results were represented as percent wound closure. (C) Representative images of hematoxylin and eosin-stained section of the regenerated wound tissue at postsurgery day 7 in various groups. (D) Quantitative analysis using NIH image J software depicted a significant increase in the number of H\&E positively stained cells in preconditioned BMSCs and HSPCs transplanted groups. (E) Representative images of Masson's trichome (MT) stained sections of the regenerated wound tissues depicting the collagen deposition. (F) Quantification of the number of MT positively stained cells in various groups. (G) A representative image of DHE-stained sections to evaluate the ROS levels at the wound site. (H) Relative mRNA expression level of antioxidant enzyme, catalase was evaluated from regenerated wound tissue by using qRT-PCR analysis. Interestingly, $10 \mu M \mathrm{H}_{2} \mathrm{O}_{2}$ preconditioned HSPCs transplanted group depicted significantly high expression of catalase. (I) Catalase activity depicted a significant increase in naive as well as $10 \mu M \mathrm{H}_{2} \mathrm{O}_{2}$ preconditioned BMSCs or HSPCs transplanted (Tx) groups as compared with the wound control at postsurgery day 7 (Wd-Cont - Wound Control, PC - Preconditioned; $n=3$ replicates per wound, $N=5$ mice/group; $p<0.05$ as compared with ${ }^{*}$ wound control; ${ }^{\#}$ BMSC or HSPC transplanted group; ${ }^{* *} p<0.01$ as compared with wound control). To see this illustration in color, the reader is referred to the web version of this article at www.liebertpub.com/ars

wound tissue using hematoxylin and eosin staining (Fig. 6C, lower magnification images-Supplementary Fig. S8A) and the quantitation of images (Fig. 6D) clearly demonstrated an increased proliferation of cells in preconditioned BMSCs and HSPCs as compared with naive BMSCs and HSPCs and/or wound-control (nonstem cells transplanted) groups. Also, the preconditioned stem cells transplanted group demonstrated an increased collagen deposition as demonstrated by Masson's Trichrome staining (Fig. 6E) and its quantitation (Fig. 6F). Overall ROS generated at the wound site was evaluated by using dihydroxy ethidium (DHE) staining. Remarkably, preconditioned BMSCs and HSPCs transplanted groups depicted a marked reduction in DHE staining as compared with naive BMSCs or HSPCs transplanted groups and the wound control (Fig. 6G). Concurrently, a significant increase in the expression of antioxidant enzymes such as MnSOD (SOD2) ( $\geq 5.5$-fold), GPx1 ( 8-fold), and GPx2 ( 3.8-fold) was observed in preconditioned HSPCs and BMSCs transplanted groups (Supplementary Fig. S8B). However, the gene expression levels did not correlate with the activity of these enzymes-SOD (Supplementary Fig. S8C) and GPx (Supplementary Fig. S8D). Interestingly, an increase in catalase gene expression in preconditioned BMSCs (10fold) and/or HSPCs (13-fold) transplanted groups (Fig. 6H) substantiated well with catalase activity (31.9 and $31.5 \mu \mathrm{mo}-$ $\mathrm{les} / \mathrm{min} / \mu \mathrm{g}$ of protein, respectively) as compared with naive 
transplanted or wound-control group (Fig. 6I). Thus, preconditioning BMSCs or HSPCs with low concentrations of $\mathrm{H}_{2} \mathrm{O}_{2}$ induced the antioxidant enzyme, catalase. These cells when transplanted at the wound site alleviated the oxidative stress, thereby promoting wound tissue regeneration.

\section{Low oxidative stress preconditioned BMSCs} and HSPCs improve engraftment at the wound site

To determine the engraftment of transplanted stem cells at the wound site, BMSCs and/or HSPCs chimera was generated by using donor cells of male $C 57 B L / 6 \mathrm{~J}$ mice transplanted onto recipient female $C 57 B L / 6 J$ mice. DNA isolated from the wound tissue at 7 days postsurgery was subjected to quantification of Y-linked zinc finger protein (Zfy-1) gene and Bcl-2 (as reference control) by using real-time PCR. Preconditioned BMSCs and HSPCs transplanted groups depicted an increased engraftment of male donor cells as compared with naive BMSCs and HSPCs transplanted groups that were abrogated when these cells were also pretreated simultaneously with an exogenous antioxidant, Vit. C (Fig. 7A). Further, engraftment of transplanted GFP-expressing BMSCs and HSPCs co-expressing other stem cell markers as reported earlier (8) were also evaluated in the regenerated wound sections. At postsurgery day 7, an increased co-localization of GFPCAT was observed in preconditioned BMSCs and HSPCs as compared with naive BMSCs and HSPCs transplanted groups, respectively, or the wound control (Fig. 7B and quantitationSupplementary Fig. S8E), thereby suggesting an increased cellular antioxidant defense mechanism in the transplanted

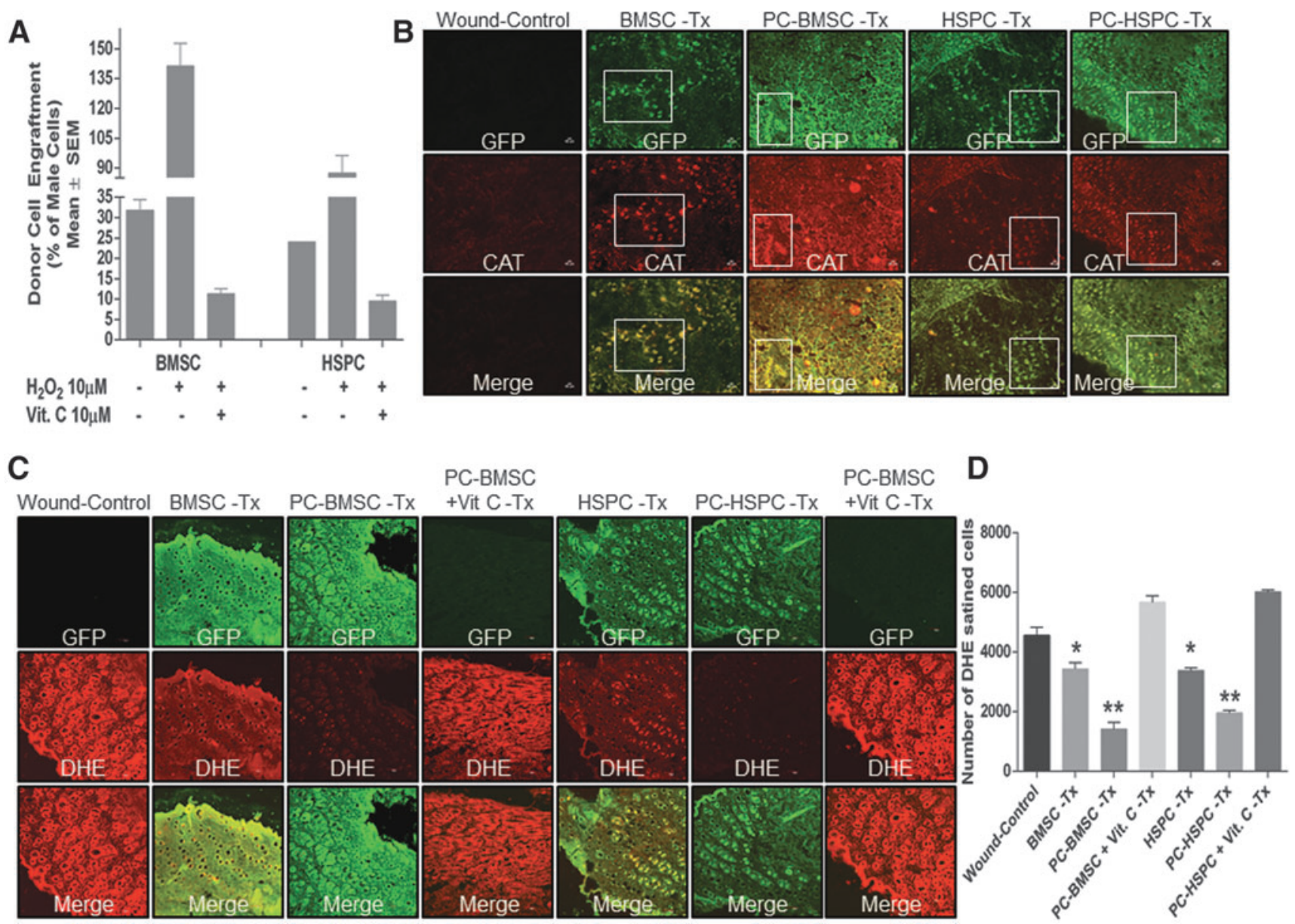

FIG. 7. Low concentration of $\mathrm{H}_{2} \mathrm{O}_{2}$-mediated preconditioning of BMSCs or HSPCs increased engraftment during transplantation. (A) Percent of male cells at the wound site when naive or preconditioned BMSCs or HSPCs were transplanted into female mice. Simultaneous treatment of Vit. C during preconditioning of BMSCs or HSPCs reversed the effect. (B) Representative images of fluorescence microscopy at lower magnification $(4 \times)$ of regenerated wound tissue sections depicting increased co-staining of catalase GFP in preconditioned BMSCs and HSPCs as compared with naive BMSCs and HSPCs, respectively, transplanted (Tx) or wound-control groups. (C) Representative confocal photomicrographs of GFP-DHE co-stained regenerated wound tissue sections of various treated groups depicting an increased engraftment of preconditioned GFP-expressing BMSCs or HSPCs led to a marked decrease in DHE staining, indicating decreased ROS levels at the wound site. Similarly, Vit. C treatment to preconditioned BMSCs or HSPCs mitigated this effect. (D) Quantitation of confocal images using NIH Image J software depicted decreased DHE staining in preconditioned BMSCs or HSPCs transplanted groups that were inhibited in the presence of simultaneous pretreatment of Vit. C (Wd-Cont - Wound Control, PC - Preconditioned; $n=3$ replicates per wound, $N=5$ mice/group; ${ }^{*} p<0.05$ as compared with wound control; ** $p<0.01$ as compared with wound control). DHE, dihydroxy ethidium. To see this illustration in color, the reader is referred to the web version of this article at www.liebertpub.com/ars 
cells. In an effort to understand whether preconditioned BMSCs and HSPCs transplanted groups with a high expression of catalase could decrease the oxidative stress, we co-stained the tissue sections with DHE. Indeed, preconditioned BMSCs and HSPCs transplanted groups depicted a marked decrease in DHE staining (Fig. 7C) as compared with naive BMSCs and HSPCs transplanted groups or the wound control (Fig. 7D). Simultaneous supplementation of Vit. $\mathrm{C}$ to $10 \mu M$ concentration of $\mathrm{H}_{2} \mathrm{O}_{2}$-mediated preconditioning of BMSCs and HSPCs in vitro when transplanted markedly decreased the engraftment of cells as evident from less GFP-positive cells and increased DHE staining. This phenomenon corroborated well with the in vitro observation (Fig. 7C, D). Next, the "antioxidant" nature of Vit. $\mathrm{C}$ as an ROS quencher was evaluated for any beneficial effects during wound repair if administered parenterally at a pharmacological dose $(200 \mathrm{mg} / \mathrm{kg}$ body wt, i.p., per day $\times 7$ days $)$. We observed a significant increase in wound closure at postsurgery day 7 as compared with the wound control (Supplementary Fig. S9A) and increased collagen deposition at the wound bed (Supplementary Fig. S9B, C). However, reports also suggest that Vit. C at a pharmacological dose acts as a "pro-oxidant" by generating ascorbate-free radicals and $\mathrm{H}_{2} \mathrm{O}_{2}$ in extracelluar fluids, which diffuse into the cells and cause depletion of ATP, thereby causing cell death (6). The BMSC and HSPC transplanted groups when administered with a pharmacological dose of Vit. C ( $200 \mathrm{mg} / \mathrm{kg}$ body wt, ip.) resulted in markedly low engraftment of cells (Supplementary Fig. S9D). BMSC and HSPC transplanted wound sections depicted a similar high DHE staining as observed in the wound-control group (Supplementary Fig. S9E, Quantitation of DHE staining-Supplementary Fig. S9F), suggesting no beneficial effect of pharmacological administration of Vit. $\mathrm{C}$ on reduction of ROS at the wound bed during wound healing. Thus, preconditioning of BMSCs and HSPCs with low concentrations of $\mathrm{H}_{2} \mathrm{O}_{2}$ before transplantation enhances the antioxidant defense system in the cells and makes them better equipped to survive the harsh wound environment.

\section{Preconditioned BMSC and HSPC enhance proliferation during wound tissue regeneration}

Next, to evaluate proliferation of the transplanted $\mathrm{GFP}^{+}$ cells, we performed co-staining with Ki67 (proliferation

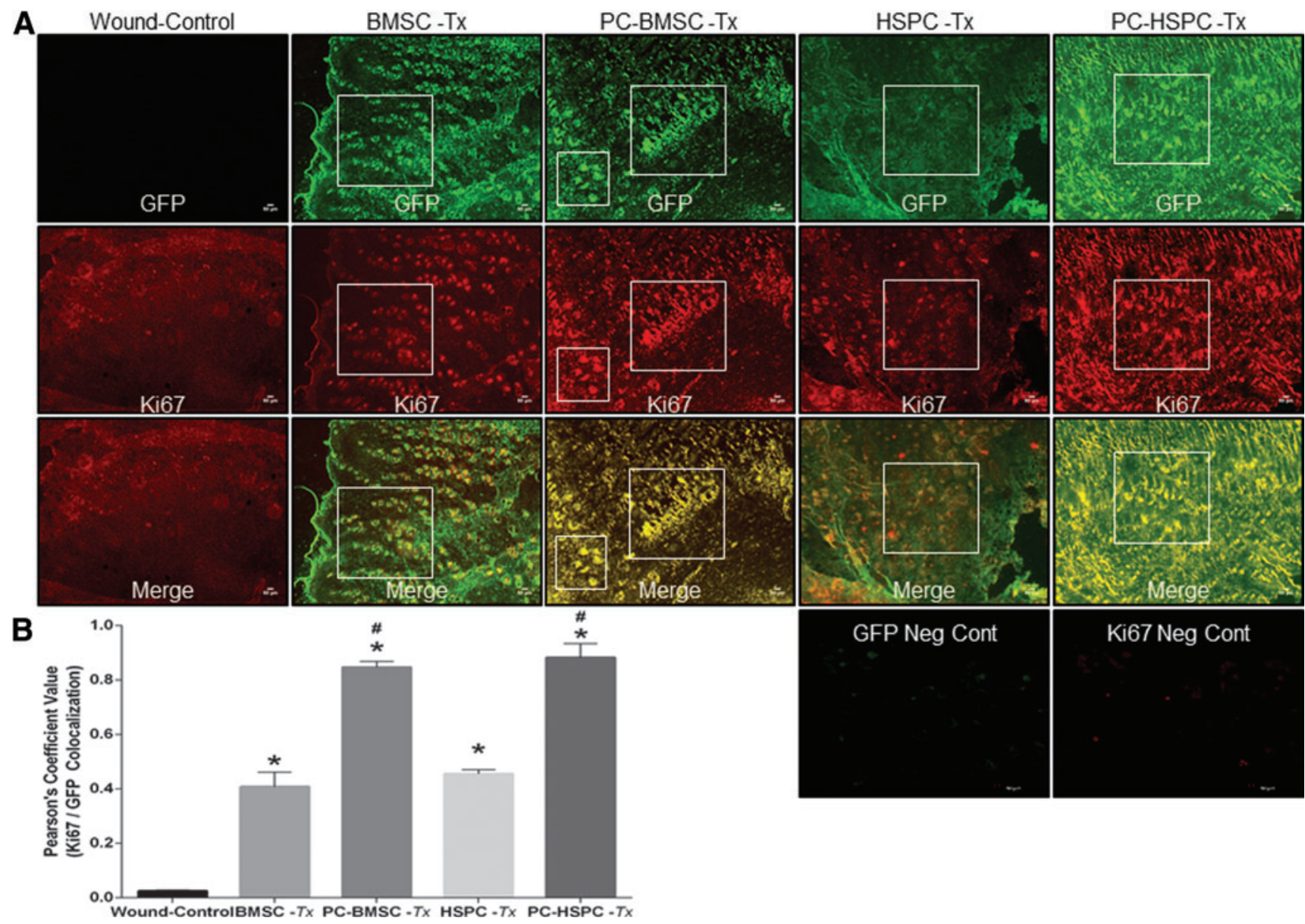

FIG. 8. Increased proliferation of preconditioned BMSCs and HSPCs improves wound healing. Representative fluorescence microscopy images at lower magnification $(4 \times)$ of wound control, naive, or $10 \mu M \mathrm{H}_{2} \mathrm{O}_{2}$ preconditioned BMSCs and HSPCs. Regenerated wound tissue section at postsurgery day 7 was co-stained with GFP and Ki67 (Insets). Preconditioned BMSCs or HSPCs transplanted wound tissues depicted a significantly high number of positively co-stained cells, suggesting higher proliferation of transplanted (Tx) cells as quantitated by intensity correlation analysis-NIH image $\mathrm{J}$ software and represented graphically (Wd-Cont - Wound Control, PC - Preconditioned; $n=3$ replicates per wound, $N=5$ mice/group; $p<0.05$ as compared with *wound control; ${ }^{*}$ naive BMSCs/HSPCs). To see this illustration in color, the reader is referred to the web version of this article at www.liebertpub.com/ars 
marker) for both BMSCs and HSPCs. At postsurgery day 7, an increased co-staining of GFP/Ki67 in preconditioned BMSCs and HSPCs transplanted groups was observed as compared with naive stem cells transplanted, respectively, and wound-control groups (Fig. 8A). Separately, we have also preconditioned both BMSCs and HSPCs with high oxidative stress $\left(100 \mu M \mathrm{H}_{2} \mathrm{O}_{2}\right)$ but it led to a decrease in proliferation (data not shown) at the wound site. These observations suggest the therapeutic relevance of $10 \mu M \mathrm{H}_{2} \mathrm{O}_{2}$ but not high concentration-induced oxidative stress in a translational outcome of BMSC and/or HSPC-mediated wound tissue repair/regeneration.

\section{Preconditioned BMSC but not HSPC enhance re-epithelialization during wound tissue regeneration}

Further, to determine whether he transplanted stem cells at the wound site could contribute to keratinocyte generation, a co-immunostaining with cytokeratin (CK) and CD29 (BMSC) or CD11b (HSPC) was performed. At postsurgery day 7, a significantly high number of CD29 and CK costained cells were observed in preconditioned BMSCs as compared with naive BMSCs transplanted groups or woundcontrol groups (Fig. 9A left panel, Quantitation of colocalization-Fig. 9B). However, naive or preconditioned HSPCs did not depict similar CD11b and CK co-stained cells (Fig. 9A right panel, Quantitation of co-localization-Fig. 9C). To further confirm whether transplanted cells contributed to keratinocyte generation, we transplanted GFP-labeled cells and performed a co-staining of GFP and CK. At postsurgery day 7, preconditioned BMSCs transplanted wounds depicted a significant increase in double-positive (both GFP-green and CK-red) staining as compared with BMSCs transplanted groups or wound controls (Fig. 9D, quantification-9E, lower magnification images-Supplementary Fig. S10A, quantification of co-localization-Supplementary Fig. S10B). However,

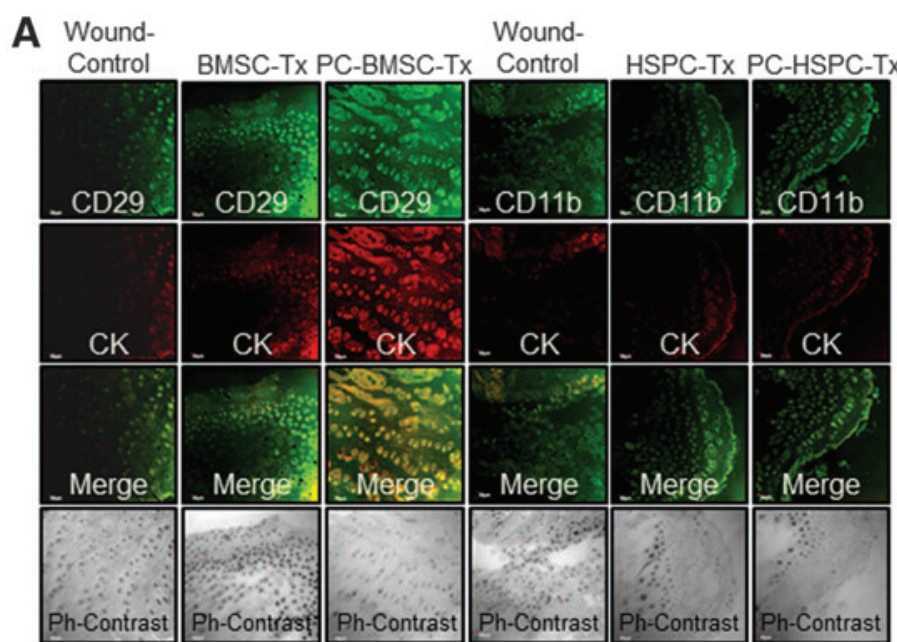

B
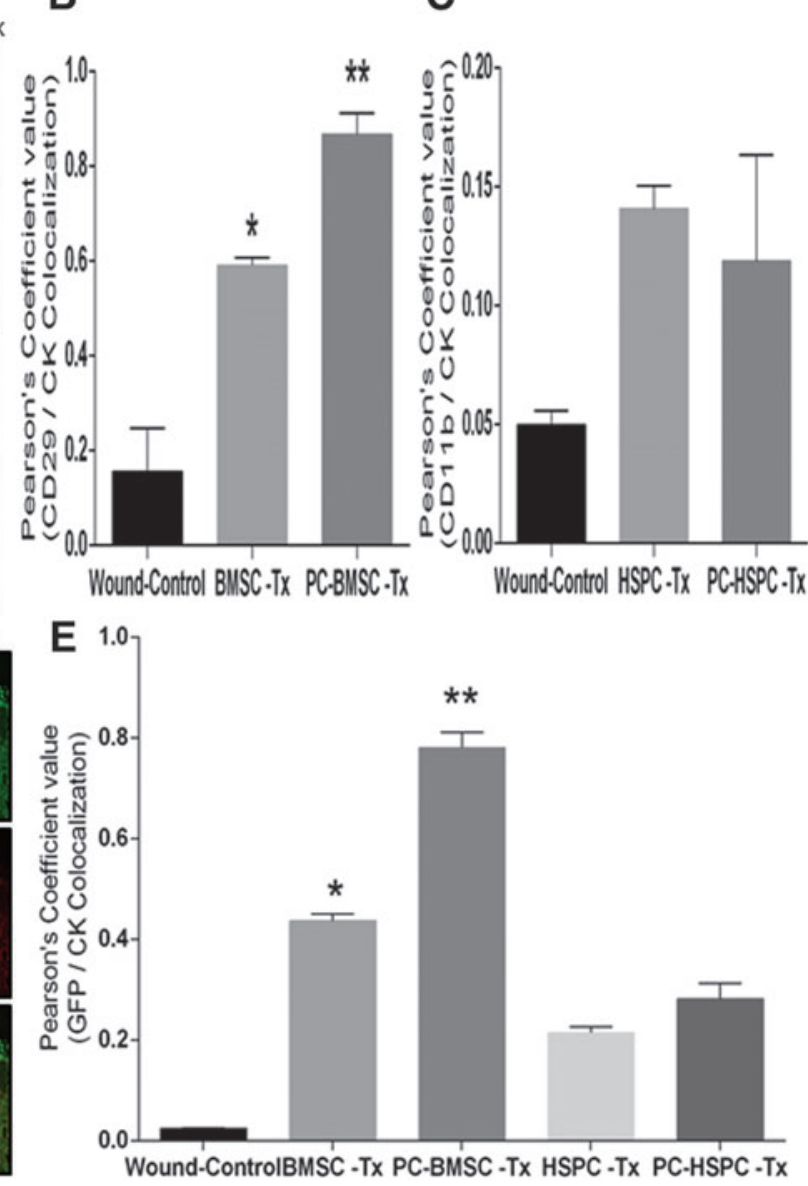

FIG. 9. Improved keratinocyte generation by preconditioned BMSCs but not HSPCs accelerates wound healing. (A) Representative confocal images depicting an increased co-staining of preconditioned BMSCs for CD29-CK (cytokeratin, a keratinocyte marker) as compared with naive BMSC transplanted (Tx) groups but not by the naive and preconditioned HSPCs transplanted groups. Quantification of the positively stained cells depicting a significant increase in BMSC transplantation group (B) but not in HSPC transplantation group (C) as compared with the respective wound-control group. (D) GFP-expressing preconditioned BMSCs or HSPCs confirmed the observation of enhanced keratinocyte generation by PC-BMSCs as compared with naive BMSCs or the wound control, whereas HSPCs transplanted (Tx) groups did not co-stain for GFP-CK. (E) Quantification of confocal images depicting an increase in the number of positively co-stained cells in various groups using intensity correlation analysis-NIH Image J software (Wd-Cont - Wound Control, PC Preconditioned; $n=3$ replicates per wound, $N=5$ mice/group; $* p<0.05$ and $* * p<0.01$ as compared with wound control). To see this illustration in color, the reader is referred to the web version of this article at www.liebertpub.com/ars 
preconditioned HSPCs transplanted wounds did not depict co-localization of GFP-CK-expressing cells (Fig. 9D, E). These observations suggest that BMSCs but not HSPCs contribute to an increased number of keratinocytes, thereby leading to cutaneous regeneration.

\section{Preconditioned BMSC and HSPC enhance vascularization during wound tissue regeneration}

Finally, neo-vascularization, a crucial step for tissue regeneration, was evaluated by using immunofluorescence staining of CD31 and $\alpha$-SMA at the regenerated tissue sections. Both preconditioned BMSCs and HSPCs transplanted wounds depicted an increased number of endothelial cells at the wound site as compared with naive BMSCs or HSPCs as well as the wound control at postsurgery day 7 (Fig. 10A, Quantitation of co-localization-Fig. 10B). Further, to evaluate the participation of these transplanted cells in vasculogenesis, tissue sections were co-stained with GFP and CD31. Preconditioned HSPCs transplanted groups depicted an increased co-staining of GFP-CD31 as compared with naive HSPCs or the wound control, indicating the involvement of HSPCs in neo-vascularization (Fig. 10C, Quantitation of co-localizationFig. 10D, lower magnification images-Supplementary Fig. S10C, quantification of co-localization-Supplementary Fig. S10D). Preconditioned BMSCs transplanted wound sections depicted an increased CD31 staining as compared with naive BMSCs or the wound control but the GFP-expressing cells were not fully colocalized with CD31-expressing cells, suggesting the paracrine effect of BMSCs that leads to enhanced vascularization at the

A

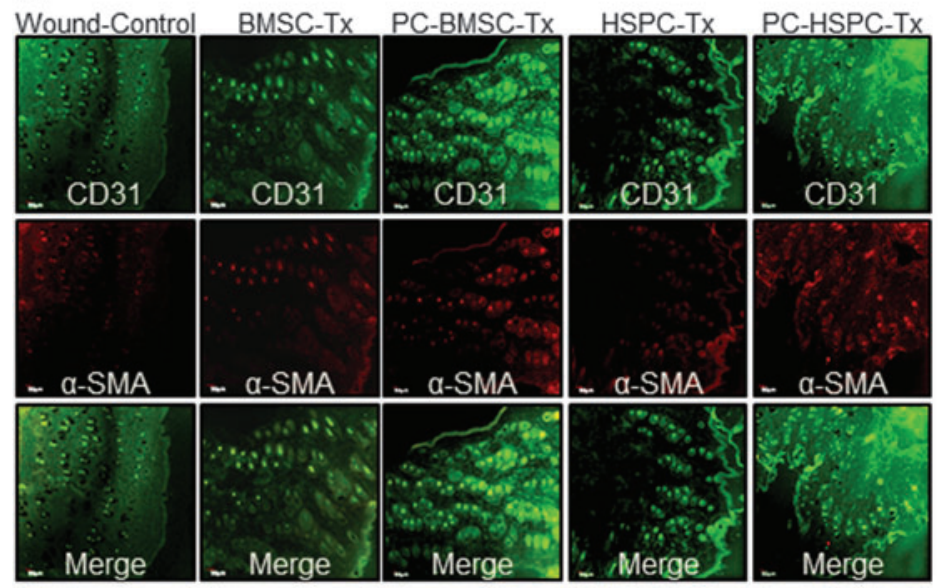

B

C
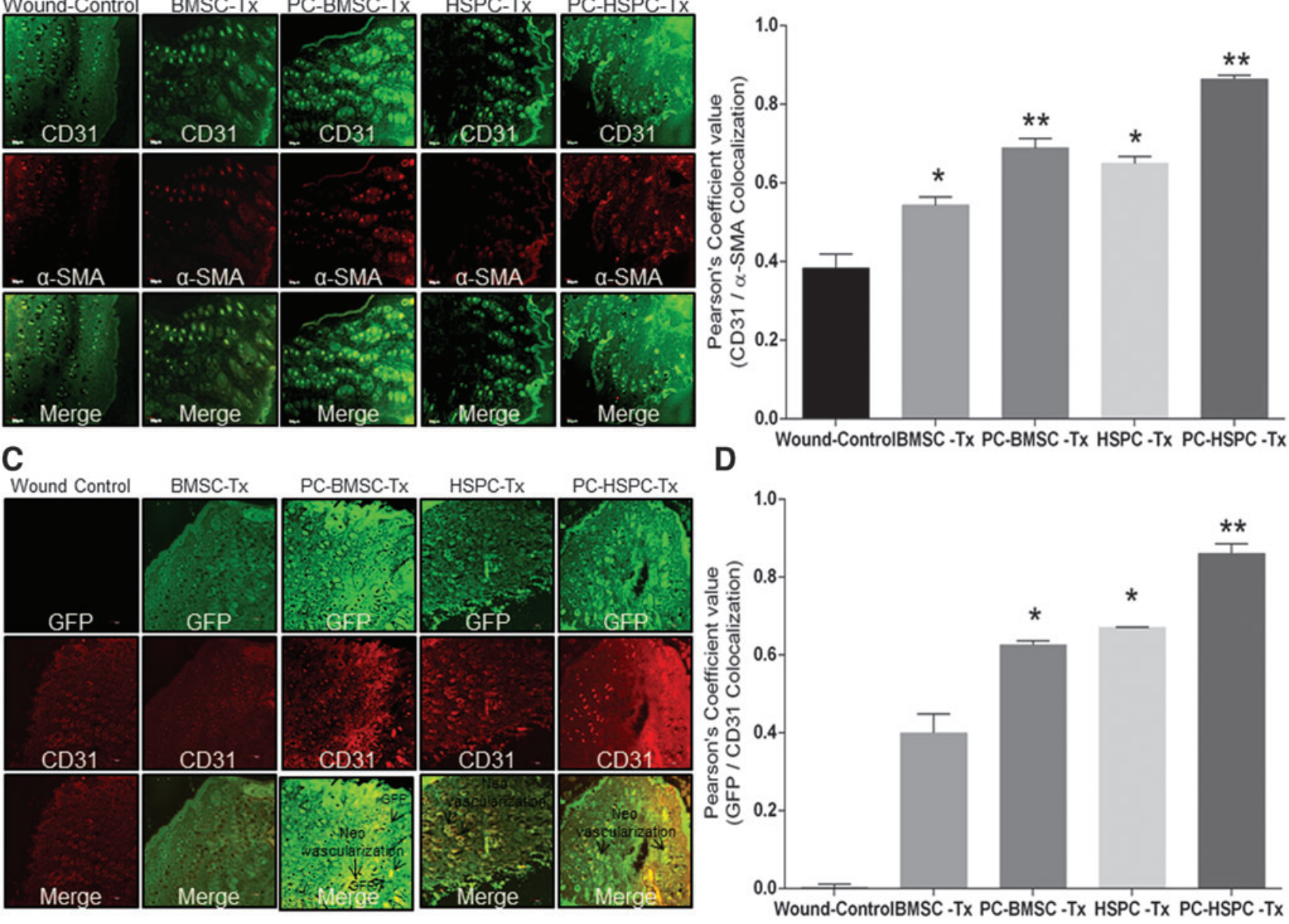

FIG. 10. Enhanced neo-vascularization by preconditioned BMSCs and HSPCs improves wound healing. (A) Representative confocal images depicting an increased co-staining of CD31- $\alpha$-SMA in preconditioned BMSCs or HSPCs transplanted (Tx) groups as compared with naive BMSCs or HSPCs transplanted groups, respectively, suggesting neovascularization during wound tissue regeneration. (B) Quantification of confocal images using intensity correlation analysisNIH Image $\mathbf{J}$ software depicting an increase in the number of positively co-stained cells in various groups. (C) Representative confocal images of GFP-expressing PC-HSPCs depicted an increased co-staining of GFP-CD31 in preconditioned HSPCs as compared with naive HSPCs, indicating neo-vascularization at the regenerated wound tissue. GFPexpressing PC-BMSCs too depicted increased staining of CD31 as compared with naive BMSCs, but all GFP-expressing cells did not co-localize with CD31, indicating a plausible paracrine effect of BMSCs in increasing vascularity in regenerated wound tissue (Wd-Cont - Wound Control, PC - Preconditioned; $n=3$ replicates per wound, $N=5$ mice/group; ${ }^{*} p<0.05$ and $* * p<0.01$ as compared with wound-control). To see this illustration in color, the reader is referred to the web version of this article at www.liebertpub.com/ars 
wound bed. This indicates the plausible role of these transplanted preconditioned stem cells in potentiating neo-vascularization to enhance wound tissue regeneration.

\section{Discussion}

Bone marrow-derived BMSCs and HSPCs are important components of regenerative medicines because of their immense potential of self-renewal, lineage-specific differentiation, as well as trans-differentiation capability that maintain homeostasis and tissue repair (18). During tissue injury, the adult stem cells migrate from the bone marrow and often get exposed to numerous kinds of stress in the injury microenvironment (24). Among these, oxidative stress plays an important role, leading to damage of cellular biomacromolecules (42). However, as mentioned earlier, level or content of the stressor defines the effect in the cell. Thus, in this study, we have evaluated the role of $10 \mu M$ and $100 \mu M$ concentration of $\mathrm{H}_{2} \mathrm{O}_{2}$-induced oxidative stress in BMSCs and HSPCs physiology. Our observations described the following: (i) $10 \mu \mathrm{M}$ concentration of $\mathrm{H}_{2} \mathrm{O}_{2}$ significantly increased proliferation of both BMSCs and HSPCs by activation of JNK-FOXO3a survival signaling pathways, leading to upregulation of catalase; (ii) exogenous Vit. $\mathrm{C}$ and its metabolized product, DHA reverted this $\mathrm{H}_{2} \mathrm{O}_{2}$-induced proliferative phenotype; (iii) mechanistically, pharmacological inhibition as well as molecular silencing of catalase sensitized these cells by decreasing cell proliferation when exposed to even $10 \mu M$ concentration of $\mathrm{H}_{2} \mathrm{O}_{2}$; (iv) $10 \mu M$ but not $100 \mu M$ concentration of $\mathrm{H}_{2} \mathrm{O}_{2}$, induces binding of FOXO3a to catalase promoter; and (v) in an in vivo model of wound tissue healing, transplantation of preconditioned BMSCs or HSPCs with $10 \mu M$ concentration of $\mathrm{H}_{2} \mathrm{O}_{2}$ depicted an increase in proliferation of engrafted cells, reepithelialization, and neo-vascularization, thereby potentiating wound tissue repair and regeneration.

Stress tolerance capacity varies extensively between stem cells and its differentiated counterparts. Literature suggests that BMSCs derived from human skin tissue as compared with skin fibroblasts are more susceptible to high concentrations of ROS at a millimolar range $(0.5-2 \mathrm{mM})$ and depict decreased viability. This susceptibility to high ROS has been attributed due to a less efficient antioxidant defense system in the stem cells (30). These studies are in alignment with our observations of reduced expression of antioxidantcatalase gene and protein in BMSCs and HSPCs when exposed to high $(100 \mu M)$ concentrations of $\mathrm{H}_{2} \mathrm{O}_{2}$. Similarly, other studies also depicted a deleterious effect of high ROS $(50 \mu M)$ generated at the ischemic site postmyocardial infarction on the adhesion properties of BMSCs (37). Although reports vary in terms of high concentrations of oxidant used, which ranges from high micromolar to low millimolar, a harmful effect on stem cell viability is generally observed. Also, adult stem cells isolated from different tissue sources might depict different susceptibility toward ROS. In contrast, studies depicting the effect of low concentrations of ROS on physiology of these adult stem cells, BMSC and HSPC are lacking in the literature. Similar to our observation, a short-term pretreatment of BMSCs with a low dose of $\mathrm{H}_{2} \mathrm{O}_{2}$ has depicted an increased therapeutic angiogenesis in the hind limb ischemia model (19). Also, Le Belle et al. have revealed the highly proliferative neural stem cell population that possesses a high amount of endogenous ROS (21). Accumulation of ROS-mediated DNA damage has been recently implicated for HSCs to exit quiescence and differentiate into hematopoietic lineages (44). Thus, the diverse cellular responses of stem cells such as proliferation, migration, differentiation, and adhesion are modulated by a low ROS concentration.

ROS such as $\mathrm{H}_{2} \mathrm{O}_{2}$ at a low concentration can act as a second messenger to regulate signal transduction (38). The signaling role of $\mathrm{H}_{2} \mathrm{O}_{2}$ is achieved when its concentration increases above the steady-state threshold level and remains elevated for a substantial period to oxidize its protein effectors. In our study, $\mathrm{H}_{2} \mathrm{O}_{2}$-induced AKT activation was limited to $10 \mu M$ concentration only. However, oxidative stressinduced activation of JNK depicted a dose-dependent effect in mediating its vital role. By contrast, $\mathrm{H}_{2} \mathrm{O}_{2}$ at a higher concentration activates p38 MAPK to decrease viability and expansion of HSPCs, resulting in premature senescence phenotype or apoptosis (15). Our data suggest a crucial role for the AKT and JNK signaling pathways.

Cells have their own antioxidant defense mechanisms to safeguard themselves from the permissible toxic levels of free radicals generated due to oxidative stress. We and others have observed that with an increase in $\mathrm{H}_{2} \mathrm{O}_{2}$ concentration to sub-lethal levels $(100 \mu M)$, the expression of mitochondrial isoform of SOD (SOD2) was induced in both BMSCs and HSPCs (2). This corresponded equally at activity level as SOD activity was further increased at sub-lethal levels, implicating its potential antioxidant role only during extreme stress conditions. On the contrary, our results of catalase mRNA expression in both BMSCs and HSPCs depicted similar findings as published earlier where the transcriptional activation of catalase was induced at a low concentration and inhibited at the sub-lethal concentration of $\mathrm{H}_{2} \mathrm{O}_{2}$ (35). This observation along with increased proliferation at $10 \mu \mathrm{M}$ but not $100 \mu M$ (sub-lethal) $\mathrm{H}_{2} \mathrm{O}_{2}$ concentration in both BMSCs and HSPCs make it more obvious to ponder on a possible role of catalase in this phenomenon.

To comprehend the underlying molecular mechanism involved in upregulation of catalase, we studied the translocation of transcription factor FOXO3a, as it is a downstream target of both AKT and JNK signaling pathways (14). FOXOs belong to the superfamily of proteins that regulate the cell fate by modulating the expression of genes involved in oxidative stress (14). A recent study depicted a direct upregulation of catalase by FOXO3a in cardiac hypertrophy (39). Although the protective role of FOXO3a in quiescent or slow cycling cells was observed by the antioxidant responsive gene, SOD2 upregulation (17), our study mechanistically suggests a catalase upregulation by FOXO3a in a transcriptional-dependent manner at $10 \mu M$ concentration of $\mathrm{H}_{2} \mathrm{O}_{2}$. Although activation of AKT occurs along with JNK at low oxidative stress, it is imperative to consider a JNKFOXO3a-mediated upregulation of antioxidant gene, catalase whereas AKT activation leads to cell proliferation (Supplementary Fig. S11A). However, catalase inhibition by 3-AT or CAT-siRNA at low oxidative stress leads to increased ROS level that inactivates AKT and, subsequently, cell proliferation. An increase in ROS to sub-lethal levels led to higher nuclear translocation of FOXO3a but decreased catalase expression and an increase in SOD2 level, indicating a plausible role of other mechanisms. 
Stem cells are emerging as a promising tool for the regenerative therapies correcting tissue damage. However, survival of transplanted stem cells is often compromised due to the harsh injury microenvironment that reduces their therapeutic efficacy (36). Cutaneous wound repair is a multifaceted process involving inflammation, angiogenesis, granular tissue formation, fibroblast proliferation, reepithelialization, and matrix remodeling (22). Perturbations in the earlier mentioned sequential steps of wound repair result in chronic or delayed wound healing in diseases such as diabetes. Literature suggests that topical administration of side population of hematopoietic stem cells as compared with main population of bone marrow cells on excisional wounds led to a better wound closure in diabetic mice as well as wildtype mice (5). Similarly, BMSCs have been reported to promote wound healing in incisional full-thickness wound healing by enhanced proliferation, differentiation, angiogenesis, and re-epithelialization during wound closure (46). $\mathrm{H}_{2} \mathrm{O}_{2}$ at a differential concentration for preconditioning BMSCs and cardiac progenitor cells has shown improved angiogenesis and better myocardial architecture (33). Our study too depicted that preconditioning of stem cells with $10 \mu M \mathrm{H}_{2} \mathrm{O}_{2}$, a concentration at which a significantly high proliferation of these cells was observed in vitro, was a promising strategy for increasing stem cell expansion of engrafted cells, in vivo. In addition, our studies are consistent with the previous literature where only BMSCs but not CD $34^{+}$cells such as our isolated HSPCs that are also CD $34^{+}$ cells (8) contributed to keratinocytes and re-epithelialization (46). Similarly, our study also depicts a substantial fraction of GFP-expressing BMSCs but not HSPCs engrafted in the wound appearing to co-express cytokeratin, suggesting a differentiation of transplanted cells into keratinocytes. Finally, the process of angiogenesis is important for supplying the survival factors for keratinocytes and newly formed granulation tissue. As demonstrated earlier by other workers, BMSC transplantation induces neo-vascularization at the wound site in a paracrine manner by secreting angiogenic growth factors (46). Our results also corroborate with the existing literature as the preconditioned BMSCs transplanted group exhibited increased CD31-expressing cells in close proximity of GFP-positive cells, whereas the preconditioned HSPCs transplanted group depicted increased GFP-CD31 co-expressing cells, suggesting their participation in neo-vascularization. The study suggests transplantation of preconditioned BMSCs and HSPCs with $10 \mu M \mathrm{H}_{2} \mathrm{O}_{2}$-mediated low oxidative stress as a therapeutic approach for enhanced wound tissue repair (Supplementary Fig. S11B).

\section{Materials and Methods}

\section{Exposure to $\mathrm{H}_{2} \mathrm{O}_{2}$}

BMSCs and HSPCs seeded at a different seeding density depending on the assay type were treated with vehicle or 1 , 10 , and $100 \mu M$ of $\mathrm{H}_{2} \mathrm{O}_{2}$ /well. Separately, BMSCs and HSPCs were incubated with equimolar concentrations of $(10 \mu M) \mathrm{H}_{2} \mathrm{O}_{2}$ along with antioxidants, Vit. C or DHA (45). In a different set of experiments, BMSCs and HSPCs were also incubated with $10 \mu M \mathrm{H}_{2} \mathrm{O}_{2}$ along with signaling pathway blockers. Further, to evaluate the loss or gain function of catalase on the cells in the presence of $\mathrm{H}_{2} \mathrm{O}_{2}$, both molecular and pharmacological interventions were applied. Cells were treated with either 3 Amino Triazole (3-AT, a catalase inhibitor) or transfected with siRNA specific toward mouse catalase gene for evaluating the effect of catalase inhibition. Similarly, cells were additionally treated with PEG-catalase to evaluate the effect of exogenous catalase (32).

\section{Cell proliferation by colony formation, growth curve, and BrdU assay}

For assessing cell expansion, BMSCs and HSPCs were plated for colony formation assay, bromodeoxyuridine (BrdU) cell proliferation assay, and growth curves at different seeding densities as described earlier [10]. For colony formation assay, BMSCs and HSPCs were cultured in complete Mesencult and Methocult medium (StemCell Technologies), respectively (16, 26). DNA synthesis was measured by using a BrdU Cell Proliferation Kit (Roche) by following the manufacturer's protocol (20). For growth curve assay, BMSCs and HSPCs were seeded at a cell density of $3 \times 10^{3}$ cells per well in at least triplicate with treatments as described earlier $(8,34)$.

\section{Quantitative real-time $P C R$}

Overall, $1.0 \mu \mathrm{g}$ of total RNA extracted from treated BMSCs and HSPCs was used for cDNA synthesis from different treatment groups by using Oligo (dT) primer of First-Strand cDNA Synthesis kit (Thermo Scientific) and mouse-specific forward and reverse primers of antioxidant and cell cycle genes (Supplementary Table S1) for quantitative real-time RT-PCR (qRT-PCR) by using Applied Biosystems Step-One Plus PCR System (Applied Biosystems) as described earlier (7). Amplification of mouse-specific eukaryotic 18S rRNA and $\beta$ Actin was used in the same reaction of all samples as an internal control. All the target gene expression was normalized to eukaryotic 18S rRNA mRNA and shown as the fold change (7).

\section{Intracellular and extracellular ROS detection}

Intracellular production of ROS was detected by fluorescence probe $2^{\prime}, 7^{\prime}$-dichloro-fluorescin diacetate (DCFH-DA; Sigma-Aldrich) as previously described (49). Briefly, after treatment for $24 \mathrm{~h}$ or $48 \mathrm{~h}$, cells were washed $3 \times$ with PBS and then incubated in $10 \mu \mathrm{M}$ DCFH-DA for $30 \mathrm{~min}$ at $37^{\circ} \mathrm{C}$. The fluorescence intensity of DCF $\left(2^{\prime}, 7^{\prime}\right.$-dichlorofluorescein) was determined on a Perkin Elmer Spectrofluorometer at excitation and emission wavelengths of 480 and $538 \mathrm{~nm}$, respectively, and background fluorescence was subtracted by using appropriate controls. For extracellular ROS detection, Hydrogen Peroxide Cell-based assay kit was used according to the manufacturer's protocol (Cayman Chemicals). After $24 \mathrm{~h}$ and $48 \mathrm{~h}$ of treatment, fluorescence intensity was measured at $530 \mathrm{~nm}$ (excitation wavelength) and $590 \mathrm{~nm}$ (emission wavelength).

\section{Total glutathione measurements}

To measure the intracellular oxidative status of stem cells, the reduced glutathione (GSH) content of each cellular protein sample was measured according to the manufacturer's protocol (Cayman Chemicals).

\section{Biochemical assay for catalase, SOD, and GPX}

Antioxidant responses of BMSCs and HSPCs were evaluated by measuring the activity of antioxidant enzymes: 
catalase, SOD, and GPX. SOD and GPX activity was measured according to the protocols provided in the Cayman assay kit (Cayman Chemicals). Catalase activity was measured by using a modified protocol of Aebi.

\section{Immunoblot analysis}

Cellular protein was extracted from BMSCs and HSPCs treated with $\mathrm{H}_{2} \mathrm{O}_{2}$ alone or in different treatment regimes as described earlier, was subjected to separation by using sodium dodecyl sulfate-poly acrylamide gel electrophoresis, transferred to PVDF membranes (Amersham Biosciences), and immunoblotted by using antibodies against phosphorylated and pan signaling markers: ERK-1/2, AKT, JNK, and p38 MAPK (ThermoScientific). Signals were detected by using the chemiluminescence ECL detection system (Merck Millipore), and visualization was performed by using G: Box (Syngene, Cambridge, United Kingdom). Quantification of protein bands was performed by using NIH Image J software (7).

\section{Cellular immunofluorescence staining-FOXO3a}

Immunofluorescent staining was performed according to a reported procedure (13). In brief, treated cells were washed with cold PBS, fixed with $4 \%$ formaldehyde for $10 \mathrm{~min}$ at $37^{\circ} \mathrm{C}$, permeabilized with $0.5 \%$ Triton $\mathrm{X}-100$ for $5 \mathrm{~min}$ at room temperature, and fixed with methanol for overnight at $4^{\circ} \mathrm{C}$. After washing with PBS, the cells were blocked with $1 \%$ BSA for $1 \mathrm{~h}$ and incubated with primary antibody FOXO3a in $1 \% \mathrm{BSA}$ for $2 \mathrm{~h}$ at room temperature. Further, secondary antirabbit PE conjugated antibody was added. Nuclei were stained with 4',6-diamidino-2-phenylindole (DAPI) contained in the mounting medium (Amresco). Confocal images were obtained with an Olympus FV1000 confocal microscope (Olympus Corp.) by using the $40 \times$ oil immersion lens. NIH Image J software was used to quantitate nuclear localization.

\section{SiRNA silencing—catalase}

For catalase knockdown, cells were transfected with siCAT or scrambled negative control according to the manufacturer's instructions by using lipofectamine 2000 (Invitrogen) (7). The cells were further treated for $48 \mathrm{~h}$ in the presence or absence of $\mathrm{H}_{2} \mathrm{O}_{2}$ and were utilized for different assays.

\section{AKT kinase assay}

BMSC and HSPCs were cultured and treated as described earlier for $48 \mathrm{~h}$ at $37^{\circ} \mathrm{C}$. Kinase activity was measured by using the In-Cell AKT ELISA Kit (Pierce), according to the manufacturer's protocol.

\section{Transient transfection of DN plasmids-AKT and JNK}

DN AKT and JNK mutant plasmids (Addgene) were transfected transiently by using lipofectamine 3000 (Invitrogen). Cells were cultured in low serum-containing medium for $48 \mathrm{~h}$ followed by various treatment regimes. After $48 \mathrm{~h}$, cells were trypsinised and utilized for different assays.

\section{ChIP assay}

ChIP assay was performed according to the manufacturer's protocol (Millipore). Cells were treated with different treatment regime, washed, and cross-linked with $1 \%$ formalde- hyde at $37^{\circ} \mathrm{C}$ for $10 \mathrm{~min}$. Cells were lysed in buffer containing a protease inhibitor cocktail, and they were sonicated by using Bioruptor (Diagenode) followed by preclearing with Protein A Agarose/Salmon sperm DNA slurry. Immunoprecipitation was performed overnight at $4^{\circ} \mathrm{C}$ with $5 \mu \mathrm{g}$ of anti-Foxo3a antibody, and this was followed by sequential washings with low-salt immune complex buffer, high-salt immune complex buffer, $\mathrm{LiCl}$ immune complex buffer, and, finally, with TE buffer. DNA was eluted from the beads and recovered by phenol/chloroform extraction and ethanol precipitation. The purified DNA was used as a template for PCR amplification.

\section{BMSC or HSPC transplantation-mediated wound healing}

Bone marrow-derived BMSCs and HSPCs isolated from C57BL/6J mice as described earlier (8) were used for autologous transplantation in the wound model as naive or post in vitro treatment using a low $(10 \mu M)$ concentration of $\mathrm{H}_{2} \mathrm{O}_{2}$ (preconditioned, $\mathrm{PC}$ ) and/or pretreatment with an equimolar concentration $(10 \mu M)$ of $\mathrm{H}_{2} \mathrm{O}_{2}$ and Vit. C. In a separate set of experiments, isolated BMSCs and HSPCs were labeled with GFP lentivirus for $24 \mathrm{~h}$ followed by replacement with fresh medium. After $48 \mathrm{~h}$, the cells were selected by "puromycinselection" and infected cells were used as naive or preconditioned as described earlier for transplantation. An excision wound splinting model was generated in 8-10 weekold $C 57 B L / 6 J$ mice as described earlier (43). Briefly, two symmetrical full-thickness excisional wounds were created beside the midline by using a 5-mm-diameter sterile biopsy punch. Transplantation of bone marrow-derived naive or preconditioned BMSCs and HSPCs was performed by injecting intradermally (id.; $0.7 \times 10^{6}$ cells) and on the wound surface $\left(0.3 \times 10^{6}\right.$ cells $)$ as previously described (9). A silicone splint was placed so that the wound was centered within the splint. An immediate-bonding adhesive was used to fix the splint to the skin, and Tegaderm was placed over the wounds. Animal experimentation protocols were approved by the Institutional animal ethics committee (approval No. IICT/CB/AD/25/06/2014/13 and IICT/CB/AD/26/08/13/08).

\section{Quantification of wound closure}

Representative digital images of wound healing depicting wound area at different time points postwound generation (days 0, 3, and 7) in wound-control, BMSC, PC-BMSC, HSPC, and PC-HSPC transplanted groups were taken. Time to wound closure was defined as the time at which the wound bed was completely re-epithelialized and filled with new tissue. Wound area was measured by tracing the wound margin and calculated by using an image analysis program (NIH Image $\mathbf{J}$ software). The results were represented as percent wound closure (1), calculated in comparison with the original size of the wound as mentioned later and described earlier (3):

$$
\text { Percent Wound Closure }=\frac{1-(\text { Wound Area })}{(\text { Original Wound Area })} \times 100
$$

The inside edge of the splint exactly matched the edge of the wound, so that the splinted hole was used to represent the original wound size. Mice were euthanized on postsurgery 
day 7; skin samples including the wound and surrounding skin were harvested by using a using a 10-mm biopsy punch.

\section{Histological and immunofluoroscence analysis of the regenerated wound}

Regenerated wound tissue samples from various treatment groups were fixed in $4 \%$ paraformaldehyde. Cross-sections of wound tissue mounted on slides were stained with hematoxylineosin, Masson's Trichrome, and DHE. The regenerated wound tissue was separately homogenized in respective assay buffers to evaluate catalase, SOD, and GPX assay. RNA extracted from wound tissue samples was utilized for gene expression of oxidative stress-associated genes by using qRT-PCR analysis. Separately, frozen wound tissue sections from the various groups were stained with specific antibodies against catalase, GFP, Ki67, CD29, CD11b, CK, CD31, and $\alpha$ SMA (Cell Signaling Technologies). Isotype control antibodies were used for negative controls. Sections were examined with Olympus FV1000 and FV10i confocal microscope. Co-localization of different cellular markers was evaluated by using the intensity correlation analysis of NIH Image J software, and data were represented as Pearson's coefficient value (1).

\section{Vit. $C$ in wound healing}

Parenteral administration of Vit. C $(250 \mathrm{mg} / \mathrm{kg}$ body wt, i.p. per day) (6) was carried out for 7 days in the excisional splinting wound model transplanted with BMSCs or HSPCs. The mice were monitored for wound healing, engraftment of transplanted cells, and histological analysis.

\section{Statistical analysis}

Data from experiments performed with repeated BMSC/ HSPC isolations at least thrice were statistically analyzed by taking mean \pm standard deviation (SD) or standard error of mean (SEM). To determine the difference between treatment group and their respective controls, Graph Pad prism version 6.05 was used to obtain statistical significance by using one- or two-way ANOVA followed by Tukey's multiple-comparison test. Blots and photomicrographs represent experiments reproduced at least thrice with similar results.

\section{Acknowledgments}

A.D. acknowledges the funding provided by CSIR, Ministry of Science and Technology, Government of India, XIIth Five-year Plan Project \# CSC-0111. Fellowships provided by ICMR and UGC are gratefully acknowledged by N.D. (ICMR-SRF) and R.G. (UGC-SRF). The authors also acknowledge the technical assistance provided by Suresh Y. in assisting flow cytometric analysis and T. Ramalinga Murthy in confocal imaging.

\section{Author Disclosure Statement}

The authors have no conflicts to disclose.

\section{References}

1. Bolte $\mathrm{S}$ and CordeliÈRes FP. A guided tour into subcellular colocalization analysis in light microscopy. J Microsc 224: 213-232, 2006.
2. Burova E, Borodkina A, Shatrova A, and Nikolsky N. Sublethal Oxidative Stress Induces the Premature Senescence of Human Mesenchymal Stem Cells Derived from Endometrium. Oxidative Med Cell Longevity 2013: 12, 2013.

3. Canesso MCC, Vieira AT, Castro TBR, Schirmer BGA, Cisalpino D, Martins FS, Rachid MA, Nicoli JR, Teixeira MM, and Barcelos LS. Skin wound healing is accelerated and scarless in the absence of commensal microbiota. $J$ Immunol 193: 5171-5180, 2014.

4. Chaanine AH, Jeong D, Liang L, Chemaly ER, Fish K, Gordon RE, and Hajjar RJ. JNK modulates FOXO3a for the expression of the mitochondrial death and mitophagy marker BNIP3 in pathological hypertrophy and in heart failure. Cell Death Dis 3: 265, 2012.

5. Chan RK, Garfein E, Gigante PR, Liu P, Agha RA, Mulligan R, and Orgill DP. Side population hematopoietic stem cells promote wound healing in diabetic mice. Plast Reconstr Surg 120: 407-411; discussion 412-413, 2007.

6. Chen Q, Espey MG, Sun AY, Lee J-H, Krishna MC, Shacter E, Choyke PL, Pooput C, Kirk KL, Buettner GR, and Levine M. Ascorbate in pharmacologic concentrations selectively generates ascorbate radical and hydrogen peroxide in extracellular fluid in vivo. Proc Natl Acad Sci U S A 104: 8749-8754, 2007.

7. Das A, Fernandez-Zapico ME, Cao S, Yao J, Fiorucci S, Hebbel RP, Urrutia R, and Shah VH. Disruption of an SP2/ KLF6 repression complex by SHP is required for Farnesoid $\mathrm{X}$ receptor-induced endothelial cell migration. $J$ Biol Chem 281: 39105-39113, 2006.

8. Dhoke NR, Kalabathula E, Kaushik K, Geesala R, Sravani $\mathrm{B}$, and Das A. Histone deacetylases differentially regulate the proliferative phenotype of mouse bone marrow stromal and hematopoietic stem/progenitor cells. Stem Cell Res 17: 170-180, 2016.

9. Geesala R, Bar N, Dhoke NR, Basak P, and Das A. Porous polymer scaffold for on-site delivery of stem cells-Protects from oxidative stress and potentiates wound tissue repair. Biomaterials 77: 1-13, 2016.

10. Geesala R, Gangasani JK, Budde M, Balasubramanian S, Vaidya JR, and Das A. 2-Azetidinones: synthesis and biological evaluation as potential anti-breast cancer agents. Eur J Med Chem 124: 544-558, 2016.

11. Gülden M, Jess A, Kammann J, Maser E, and Seibert H. Cytotoxic potency of $\mathrm{H} 2 \mathrm{O} 2$ in cell cultures: impact of cell concentration and exposure time. Free Radic Biol Med 49: 1298-1305, 2010.

12. Henklova P, Vrzal R, Papouskova B, Bednar P, Jancova P, Anzenbacherova E, Ulrichova J, Maurel P, Pavek P, and Dvorak Z. SB203580, a pharmacological inhibitor of p38 MAP kinase transduction pathway activates ERK and JNK MAP kinases in primary cultures of human hepatocytes. Eur J Pharmacol 593: 16-23, 2008.

13. Ho K-K, McGuire VA, Koo C-Y, Muir KW, de Olano N, Maifoshie E, Kelly DJ, McGovern UB, Monteiro LJ, Gomes AR, Nebreda AR, Campbell DG, Arthur JSC, and Lam EW-F. Phosphorylation of FOXO3a on Ser-7 by p38 promotes its nuclear localization in response to doxorubicin. J Biol Chem 287: 1545-1555, 2012.

14. Huang $\mathrm{H}$ and Tindall DJ. Dynamic FoxO transcription factors. J Cell Sci 120: 2479-2487, 2007.

15. Ito K, Hirao A, Arai F, Takubo K, Matsuoka S, Miyamoto K, Ohmura M, Naka K, Hosokawa K, Ikeda Y, and Suda T. 
Reactive oxygen species act through p38 MAPK to limit the lifespan of hematopoietic stem cells. Nat Med 12: 446451, 2006.

16. Kaufman DS, Hanson ET, Lewis RL, Auerbach R, and Thomson JA. Hematopoietic colony-forming cells derived from human embryonic stem cells. Proc Natl Acad Sci USA 98: 10716-10721, 2001.

17. Kops GJPL, Dansen TB, Polderman PE, Saarloos I, Wirtz KWA, Coffer PJ, Huang T-T, Bos JL, Medema RH, and Burgering BMT. Forkhead transcription factor FOXO3a protects quiescent cells from oxidative stress. Nature 419: 316-321, 2002.

18. Körbling $\mathrm{M}$ and Estrov Z. Adult Stem Cells for Tissue Repair-A New Therapeutic Concept? N Engl J Med 349: 570-582, 2003.

19. Kubo M, Li T-S, Suzuki R, Ohshima M, Qin S-L, and Hamano K. Short-term pretreatment with low-dose hydrogen peroxide enhances the efficacy of bone marrow cells for therapeutic angiogenesis. Am J Physiol Heart Circ Physiol 292: H2582-H2588, 2007.

20. Lau CP, Ng PK, Li MS, Tsui SK, Huang L, and Kumta SM. p63 regulates cell proliferation and cell cycle progressionassociated genes in stromal cells of giant cell tumor of the bone. Int J Oncol 42: 437-43, 2013.

21. Le Belle JE, Orozco NM, Paucar AA, Saxe JP, Mottahedeh J, Pyle AD, Wu H, and Kornblum HI. Proliferative neural stem cells have high endogenous ROS levels that regulate self-renewal and neurogenesis in a PI3K/Akt-dependant manner. Cell Stem Cell 8: 59-71.

22. Lee DE, Ayoub N, and Agrawal DK. Mesenchymal stem cells and cutaneous wound healing: novel methods to increase cell delivery and therapeutic efficacy. Stem Cell Res Ther 7: 1-8, 2016.

23. Liang Q, Bueno OF, Wilkins BJ, Kuan CY, Xia Y, and Molkentin JD. c-Jun N-terminal kinases (JNK) antagonize cardiac growth through cross-talk with calcineurin-NFAT signaling. EMBO J 22: 5079-5089, 2003.

24. Lo EH, Wang X, and Cuzner ML. Extracellular proteolysis in brain injury and inflammation: role for plasminogen activators and matrix metalloproteinases. J Neurosci Res 69: 1-9, 2002.

25. Mackintosh C. Dynamic interactions between 14-3-3 proteins and phosphoproteins regulate diverse cellular processes. Biochem J 381: 329-342, 2004.

26. Meirelles Lda $\mathrm{S}$ and Nardi NB. Murine marrow-derived mesenchymal stem cell: isolation, in vitro expansion, and characterization. Br J Haematol 123: 702-711, 2003.

27. Michiels C, Raes M, Toussaint O, and Remacle J. Importance of SE-glutathione peroxidase, catalase, and CU/ ZN-SOD for cell survival against oxidative stress. Free Radic Biol Med 17: 235-248, 1994.

28. Montecinos V, Guzmán P, Barra V, Villagrán M, MuñozMontesino C, Sotomayor K, Escobar E, Godoy A, Mardones L, Sotomayor P, Guzmán C, Vásquez O, Gallardo V, van Zundert B, Bono MR, Oñate SA, Bustamante M, Cárcamo JG, Rivas CI, and Vera JC. Vitamin C is an essential antioxidant that enhances survival of oxidatively stressed human vascular endothelial cells in the presence of a vast molar excess of glutathione. J Biol Chem 282: 15506-15515, 2007.

29. Nathan C and Ding A. SnapShot: reactive oxygen intermediates (ROI). Cell 140: 951-951.e2.

30. Orciani M, Gorbi S, Benedetti M, Di Benedetto G, Mattioli-Belmonte M, Regoli F, and Di Primio R. Oxida- tive stress defense in human-skin-derived mesenchymal stem cells versus human keratinocytes: different mechanisms of protection and cell selection. Free Radic Biol Med 49: 830-838, 2010.

31. Parmar K, Mauch P, Vergilio J-A, Sackstein R, and Down JD. Distribution of hematopoietic stem cells in the bone marrow according to regional hypoxia. Proc Natl Acad Sci U S A 104: 5431-5436, 2007.

32. Paulsen CE, Truong TH, Garcia FJ, Homann A, Gupta V, Leonard SE, and Carroll KS. Peroxide-dependent sulfenylation of the EGFR catalytic site enhances kinase activity. Nat Chem Biol 8: 57-64, 2011.

33. Pendergrass KD, Boopathy AV, Seshadri G, MaiellaroRafferty K, Che PL, Brown ME, and Davis ME. Acute preconditioning of cardiac progenitor cells with hydrogen peroxide enhances angiogenic pathways following ischemia-reperfusion injury. Stem Cells Dev 22: 2414-24, 2013.

34. Peng L, Jia Z, Yin X, Zhang X, Liu Y, Chen P, Ma K, and Zhou C. Comparative analysis of mesenchymal stem cells from bone marrow, cartilage, and adipose tissue. Stem Cells Dev 17: 761-73, 2008.

35. Quan X, Lim S-O, and Jung G. Reactive oxygen species downregulate catalase expression via methylation of a $\mathrm{CpG}$ Island in the Oct-1 promoter. FEBS Lett 585: 3436-3441, 2011.

36. Sart S, Ma T, and Li Y. Preconditioning stem cells for in vivo delivery. BioRes Open Access 3: 137-149, 2014.

37. Song H, Cha M-J, Song B-W, Kim I-K, Chang W, Lim S, Choi EJ, Ham O, Lee S-Y, Chung N, Jang Y, and Hwang $\mathrm{K}-\mathrm{C}$. Reactive oxygen species inhibit adhesion of mesenchymal stem cells implanted into ischemic myocardium via interference of focal adhesion complex. Stem Cells 28: 555-563, 2010.

38. Stone JR and Yang S. Hydrogen peroxide: a signaling messenger. Antioxid Redox Signal 8: 243-70, 2006.

39. Tan W-Q, Wang K, Lv D-Y, and Li P-F. Foxo3a inhibits cardiomyocyte hypertrophy through transactivating catalase. J Biol Chem 283: 29730-29739, 2008.

40. Truong TH and Carroll KS. Redox regulation of EGFR signaling through cysteine Oxidation(). Biochemistry 51: 9954-9965, 2012.

41. Ueda M, Kinoshita H, Yoshida T, Kamasawa N, Osumi M, and Tanaka A. Effect of catalase-specific inhibitor 3amino-1,2,4-triazole on yeast peroxisomal catalase in vivo. FEMS Microbiol Lett 219: 93-98, 2003.

42. Urao $N$ and Ushio-Fukai M. Redox regulation of stem/ progenitor cells and bone marrow niche. Free Radic Biol Med 54: 26-39, 2013.

43. Wang X, Ge J, Tredget EE, and Wu Y. The mouse excisional wound splinting model, including applications for stem cell transplantation. Nat Protocols 8: 302-309, 2013.

44. Weiss C and Ito K. DNA Damage: a sensible mediator of the differentiation decision in hematopoietic stem cells and in leukemia. Int J Mol Sci 16: 6183, 2015.

45. Wilson JX. The physiological role of dehydroascorbic acid. FEBS Lett 527: 5-9, 2002.

46. Wu Y, Chen L, Scott PG, and Tredget EE. Mesenchymal stem cells enhance wound healing through differentiation and angiogenesis. Stem Cells 25: 2648-2659, 2007.

47. Xie R, Cheng M, Li M, Xiong X, Daadi M, Sapolsky RM, and Zhao $\mathrm{H}$. Akt isoforms differentially protect against 
stroke-induced neuronal injury by regulating mTOR activities. J Cereb Blood Flow Metab 33: 1875-1885, 2013.

48. Zelivianski S, Spellman M, Kellerman M, Kakitelashvilli V, Zhou X-W, Lugo E, Lee M-S, Taylor R, Davis TL, Hauke R, and Lin M-F. ERK inhibitor PD98059 enhances docetaxel-induced apoptosis of androgen-independent human prostate cancer cells. Int J Cancer 107: 478-485, 2003.

49. Zeng W, Xiao J, Zheng G, Xing F, Tipoe GL, Wang X, He C, Chen Z-Y, and Liu Y. Antioxidant treatment enhances human mesenchymal stem cell anti-stress ability and therapeutic efficacy in an acute liver failure model. Sci Rep 5: 11100, 2015.

Address correspondence to:

Dr. Amitava Das

Centre for Chemical Biology CSIR-Indian Institute of Chemical Technology

Uppal Road

Hyderabad 500007

India

E-mail: amitavadas@iict.res.in; amitavadas.iict@gov.in

Date of first submission to ARS Central, December 16, 2016; date of final revised submission, August 19, 2017; date of acceptance, August 20, 2017.

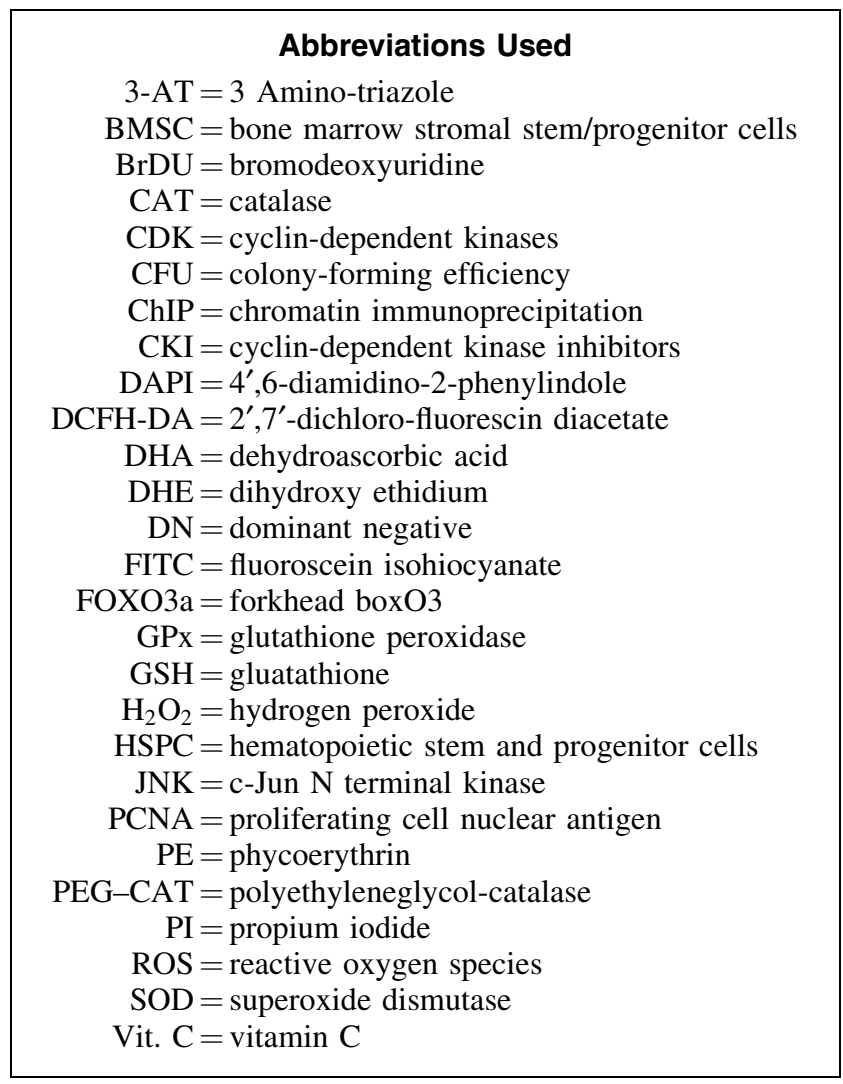

